\title{
Street-scale air quality modelling for Beijing during a winter 2016 measurement campaign
}

\author{
Michael Biggart ${ }^{1}$, Jenny Stocker ${ }^{2}$, Ruth M. Doherty ${ }^{1}$, Oliver Wild ${ }^{3}$, Michael Hollaway ${ }^{3, a}$, David Carruthers ${ }^{2}, \mathrm{Jie} \mathrm{Li}^{4}$, \\ Qiang Zhang ${ }^{5}$, Ruili Wu ${ }^{5}$, Simone Kotthaus ${ }^{6,7}$, Sue Grimmond ${ }^{6}$, Freya A. Squires ${ }^{8}$, James Lee ${ }^{8,9}$, and Zongbo Shi ${ }^{10,11}$ \\ ${ }^{1}$ School of Geosciences, University of Edinburgh, Edinburgh, UK \\ ${ }^{2}$ Cambridge Environmental Research Consultants, Cambridge, UK \\ ${ }^{3}$ Lancaster Environment Centre, Lancaster University, Lancaster, UK \\ ${ }^{4}$ State Key Laboratory of Atmospheric Boundary Layer Physics and Atmospheric Chemistry, \\ Institute of Atmospheric Physics, Chinese Academy of Sciences, Beijing, China \\ ${ }^{5}$ Ministry of Education Key Laboratory for Earth System Modelling, Department of Earth System Science, \\ Tsinghua University, Beijing, China \\ ${ }^{6}$ Department of Meteorology, University of Reading, Reading, UK \\ ${ }^{7}$ Institut Pierre Simon Laplace, École Polytechnique, Palaiseau, France \\ ${ }^{8}$ Wolfson Atmospheric Chemistry Laboratories, Department of Chemistry, University of York, York, UK \\ ${ }^{9}$ National Centre for Atmospheric Science, University of York, York, UK \\ ${ }^{10}$ School of Geography Earth and Environmental Sciences, University of Birmingham, Birmingham, UK \\ ${ }^{11}$ Institute of Surface-Earth System Science, Tianjin University, Tianjin, China \\ a now at: Centre for Ecology \& Hydrology, Lancaster Environment Centre, Bailrigg, Lancaster, UK
}

Correspondence: Michael Biggart (michael.biggart@ed.ac.uk)

Received: 30 August 2019 - Discussion started: 30 September 2019

Revised: 29 January 2020 - Accepted: 1 February 2020 - Published: 5 March 2020

\begin{abstract}
We examine the street-scale variation of $\mathrm{NO}_{x}$, $\mathrm{NO}_{2}, \mathrm{O}_{3}$ and $\mathrm{PM}_{2.5}$ concentrations in Beijing during the Atmospheric Pollution and Human Health in a Chinese Megacity (APHH-China) winter measurement campaign in November-December 2016. Simulations are performed using the urban air pollution dispersion and chemistry model ADMS-Urban and an explicit network of road source emissions. Two versions of the gridded Multi-resolution Emission Inventory for China (MEIC v1.3) are used: the standard MEIC v1.3 emissions and an optimised version, both at $3 \mathrm{~km}$ resolution. We construct a new traffic emissions inventory by apportioning the transport sector onto a detailed spatial road map. Agreement between mean simulated and measured pollutant concentrations from Beijing's air quality monitoring network and the Institute of Atmospheric Physics (IAP) field site is improved when using the optimised emissions inventory. The inclusion of fast $\mathrm{NO}_{x}-\mathrm{O}_{3}$ chemistry and explicit traffic emissions enables the sharp concentration gradients adjacent to major roads to be resolved with the model. How-
\end{abstract}

ever, $\mathrm{NO}_{2}$ concentrations are overestimated close to roads, likely due to the assumption of uniform traffic activity across the study domain. Differences between measured and simulated diurnal $\mathrm{NO}_{2}$ cycles suggest that an additional evening $\mathrm{NO}_{x}$ emission source, likely related to heavy-duty diesel trucks, is not fully accounted for in the emissions inventory. Overestimates in simulated early evening $\mathrm{NO}_{2}$ are reduced by delaying the formation of stable boundary layer conditions in the model to replicate Beijing's urban heat island. The simulated campaign period mean $\mathrm{PM}_{2.5}$ concentration range across the monitoring network $\left(\sim 15 \mu \mathrm{g} \mathrm{m}^{-3}\right)$ is much lower than the measured range $\left(\sim 40 \mu \mathrm{g} \mathrm{m}^{-3}\right)$. This is likely a consequence of insufficient $\mathrm{PM}_{2.5}$ emissions and spatial variability, neglect of explicit point sources, and assumption of a homogeneous background $\mathrm{PM}_{2.5}$ level. Sensitivity studies highlight that the use of explicit road source emissions, modified diurnal emission profiles, and inclusion of urban heat island effects permit closer agreement between simulated and measured $\mathrm{NO}_{2}$ concentrations. This work lays the 
foundations for future studies of human exposure to ambient air pollution across complex urban areas, with the APHHChina campaign measurements providing a valuable means of evaluating the impact of key processes on street-scale air quality.

\section{Introduction}

In recent decades, China's rapid economic growth, industrialisation and urbanisation have led to severely deteriorating air quality. Associations between high concentrations of air pollutant species, such as fine particulate matter $\left(\mathrm{PM}_{2.5}\right)$, nitrogen oxides $\left(\mathrm{NO}_{x}=\mathrm{NO}+\mathrm{NO}_{2}\right)$ and ozone $\left(\mathrm{O}_{3}\right)$, and adverse health effects are well-established in China (Han et al., 2018). Most notably, the inhalation of ambient $\mathrm{PM}_{2.5}$ is linked to respiratory illnesses, cardiovascular disease, lung cancer and adverse birth outcomes (Han et al., 2018; Liang et al., 2019). The Global Burden of Disease Study 2016 identified ambient $\mathrm{PM}_{2.5}$ exposure as the fourth leading cause of premature death in China (GBD 2016 Risk Factors Collaborators, 2017).

To accurately assess the extent of human exposure to pollution in densely populated and complex urban areas and to reduce this health risk, comprehensive information is needed on the spatiotemporal variation of ambient pollutant concentrations, the dominant emission source sectors, chemical processes and the role of meteorological conditions in pollution accumulation and dispersion. High-quality air pollutant concentration measurements can provide some of the required information. For instance in Beijing, a 35-station automated air quality monitoring network has measured continuous hourly concentrations of $\mathrm{PM}_{2.5}, \mathrm{PM}_{10}, \mathrm{SO}_{2}, \mathrm{NO}_{2}, \mathrm{O}_{3}$ and CO since 2013. However, these measurements, recorded by Beijing's Environment Protection Bureau (EPB), are sparsely distributed (Chen et al., 2015; Li et al., 2018; Cui et al., 2019). This, coupled with the sharp pollutant concentration gradients that exist across urban areas (Hood et al., 2018), limits the accuracy of any subsequent human exposure analyses. Therefore, air quality modelling, evaluated using network measurements, may fill in the gaps to provide complete spatially and temporally resolved concentration fields (Bates et al., 2018).

Air quality modelling, from global to street scale, requires detailed representations of local and regional emission fields. However, generating accurate and up-to-date emissions data is a considerable challenge, owing to difficulties in obtaining the necessary activity, emission factor, and production/control technology data for each emission source sector (Hong et al., 2017; Qi et al., 2017). Additionally, in China, the rapid decrease in emissions of major air pollutants over recent years needs to be accounted for (Sun et al., 2018; Zheng et al., 2018). This reduction in emissions has followed the nationwide implementation of a number of clean air policies since 2013 as part of the Air Pollution Prevention and Control Action Plan (APPCAP) and more locally through the Beijing Action Plan (Ni et al., 2018; Cheng et al., 2019; Wang et al., 2019). Overall, emissions in Beijing of $\mathrm{SO}_{2}, \mathrm{NO}_{x}$, VOCs and $\mathrm{PM}_{2.5}$ are reported to have decreased by $84 \%, 43 \%, 42 \%$ and $55 \%$ between 2013 and 2017 (Cheng et al., 2019). These emission reductions were estimated by Cheng et al. (2019), using the technology-based model framework of the Multi-resolution Emission Inventory for China (MEIC), and are in good agreement with independent satellite-derived emission trends (Liu et al., 2016, 2017).

The MEIC emission inventory is widely used in studies aimed at understanding the key emission sources and the effectiveness of air pollution control measures across various regions of China (Li et al., 2017; Zheng et al., 2018; Cheng et al., 2019). However, uncertainties in MEIC emissions estimates, related to their underlying methodology and input data, have also been highlighted. For instance, the MEIC model relies on the use of national and provincial energy consumption statistics, which were shown by Hong et al. (2017) to contain large sources of error. The MEIC model uses spatial proxies, such as gross domestic product (GDP) and urban population density, to downscale emissions from provincialto county- and grid-level scale (Qi et al., 2017). A study by Zheng et al. (2017) revealed a tendency to over-allocate emissions to central urban areas when using these spatial proxies to produce the MEIC inventory at resolutions finer than $0.25^{\circ}$. Zheng et al. (2017) attributed this to the displacement of large industrial facilities away from urban centres, therefore decoupling the real-world locations of the emissions from the population-related proxies used to represent them in the MEIC inventory.

Numerous regional modelling studies, incorporating emission inventories such as MEIC and Eulerian chemical transport models (CTMs), have been carried out for Beijing (Liu et al., 2016; Petaja et al., 2016; Li et al., 2017; Y. Wang et al., 2017, 2018; Chang et al., 2019). A key limitation of regional models, however, is that they cannot be used to represent pollutant concentrations at the scale needed to fully assess human health impacts. As a result, a range of streetscale-resolution air quality modelling techniques have recently emerged. Land use regression (LUR) modelling studies, combining geospatial indicators with air quality measurement data, can generate local-scale $(<1 \mathrm{~km})$ pollutantlevel variations, but have been limited by the sparsity of monitoring network data available in Beijing (J. Xu et al., 2019; M. Xu et al., 2019). Alternatively, box models, such as the Model of Urban Network of Intersecting Canyons and Highways (MUNICH), are used to calculate pollutant concentrations within street canyons, but require detailed information on the spatial dimensions of a city's street canyons and are restricted by assumptions of uniform concentrations along individual road segments (Lugon et al., 2019). Gaussian plume dispersion models, capable of simulating dispersion from an array of explicitly represented emission source types, includ- 
ing road and point sources, are instead often implemented. Widely used for environmental regulatory purposes, models such as ADMS-Urban (Owen et al., 2000) and AERMOD (Cimorelli et al., 2005) incorporate detailed boundary layer parameterisations and transport processes. The additional modelling of local fast chemistry processes on pollutant emissions with ADMS-Urban, involving the simplified Generic Reaction Set (GRS) chemistry scheme, including $\mathrm{NO}_{x}-\mathrm{O}_{3}$ reactions, enables sharp concentration gradients adjacent to major urban sources to be captured (Hood et al., 2018). Previous applications of ADMS-Urban in China have largely focussed on evaluating the impact that emission control schemes targeting individual sources have on the immediate environment. For instance, Chen et al. (2009) combined pollutant concentrations simulated by ADMS-Urban with population data to investigate the impact of traffic control policies on human exposure levels in Shanghai. Similarly, Cai and Xie (2011) used the ADMS-Urban model to quantify the effect that the odd-even traffic scheme (restricting vehicles with odd or even number plates), enforced during the 2008 Olympics, had on emissions from a selection of major roads, finding that some of the previously most polluted areas subsequently complied with the Chinese National Air Quality Standards (CNAAQS).

This study aims to produce, for the first time, fully resolved street-scale $\mathrm{NO}_{2}, \mathrm{O}_{3}$ and $\mathrm{PM}_{2.5}$ concentrations across urban and suburban Beijing using ADMS-Urban and explicit source road traffic emissions. Previously, Yang et al. (2019) used the RapidAir dispersion model in Beijing, which excludes chemical processes, and a link-level traffic emissions inventory developed using congestion maps and manual vehicle counts to simulate pollutant concentrations at the street level. A bottom-up street-scale vehicle emissions inventory was also created by Y. Zhang et al. (2018), using traffic surveys and video identification of vehicle fleet composition, to evaluate the impact of a new low-emission zone (LEZ) in urban Beijing. For this study, we compile an explicit source traffic emissions inventory by apportioning gridded emissions onto the freely available OpenStreetMap (OSM) road network geometry. Unlike the data-intensive methodologies adopted by Y. Zhang et al. (2018) and Yang et al. (2019), spatiotemporal variations in traffic volume and vehicle type are not considered here. However, this work provides a robust framework suitable for similar street-scale air quality modelling across large urban areas with limited data availability that future human health studies can build on. Furthermore, both the MEIC v1.3 and an optimised version of the same inventory are used to assess the performance of proxybased inventories for street-scale modelling. Aggregated sectoral emissions (industrial, power and residential) are also included. We perform simulations for the Atmospheric Pollution and Human Health in a Chinese megacity (APHHChina) winter measurement campaign period, which took place in November-December 2016 at the Institute of Atmospheric Physics (IAP), Chinese Academy of Sciences (Shi et al., 2019). Measured pollutant concentrations from both the APHH-China campaign and Beijing's air quality monitoring network are used to evaluate modelled concentrations, providing valuable insight into the key processes that impact street-scale air quality. The adaptability of ADMS-Urban is utilised in a series of further sensitivity simulations aimed at exploring the impact that explicit road traffic emissions, modified diurnal emissions profiles and Beijing's evening urban heat island (UHI) have on discrepancies between measured and modelled pollutant concentrations.

A detailed description of the ADMS-Urban model and its inputs is provided in Sect. 2. Section 3 presents an evaluation and discussion of results comparing modelled concentrations, using both emission inventories, with monitoring network and field campaign measurement data. A summary of this work's primary findings is provided in Sect. 4 along with details of possible future study development.

\section{Methodology}

The street-scale air pollution dispersion and chemistry model, ADMS-Urban, is used here to simulate ambient concentrations of $\mathrm{NO}_{x}, \mathrm{NO}_{2}, \mathrm{O}_{3}$ and $\mathrm{PM}_{2.5}$ across Beijing during the APHH-China winter campaign period (5 November 2016-10 December 2016). Section 2.1 provides a full description of the model and its configuration for Beijing, including details on emission source types, pollution dispersion, chemical processes and background pollutant concentrations. Emission inventory development, including the construction of an explicit network of road source emissions, is outlined in Sect. 2.2. In Sect. 2.3, the statistical measures used to evaluate model performance are described.

\subsection{Model description and set-up}

ADMS-Urban, developed by Cambridge Environmental Research Consultants (CERC), is a quasi-Gaussian pollution dispersion and chemistry model that has been applied worldwide for environmental regulation, investigation and assessment of emission control strategies and generation of high spatial resolution air quality forecasts (McHugh et al., 2005; Carruthers, 2009; Cai and Xie, 2011).

The model domain $(75 \mathrm{~km} \times 90 \mathrm{~km})$ covers urban Beijing, defined here as everywhere within the Sixth Ring Road (marked in Fig. 1), and extends into the suburban counties of Shunyi and Changping to the north and Tongzhou, Daxing and Fangshan to the south, as illustrated by Fig. 1.

\subsubsection{Emission sources, meteorological inputs and surface parameters}

In the model, pollutant emissions are represented as individual plumes dispersing from a range of explicitly represented sources, including point, road, area and volume sources. Aggregate grid sources (2-D and 3-D) are used to account for 


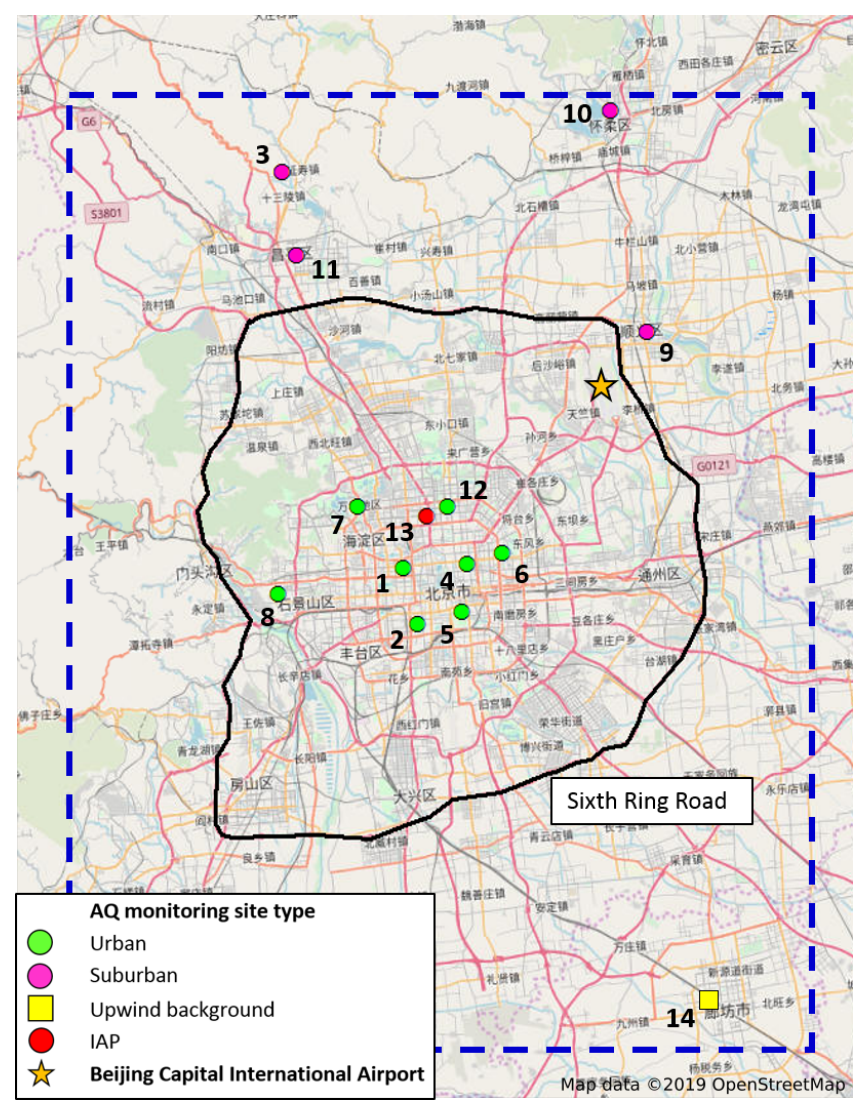

Figure 1. Map of Beijing (source: OpenStreetMap, 2019) with the modelling domain, measuring $75 \mathrm{~km} \times 90 \mathrm{~km}$, outlined (dashed blue line). Urban (green circle), suburban (pink circle), upwind background (yellow square) and IAP (red circle) air quality monitoring station locations, including site numbers, are provided. Beijing Capital International Airport (yellow star) and the Sixth Ring Road (black line) are also highlighted. (C) OpenStreetMap contributors 2019. Distributed under a Creative Commons BY-SA License.

additional, poorly defined diffuse emissions (e.g. domestic heating or minor roads) (Mohan et al., 2011; Dédelé and Miskinyté, 2015; Hood et al., 2018). Plume dispersion calculations are driven by a single set of meteorological measurements that are representative of upwind conditions and assumed to be homogeneous across the study domain. For this study, we use hourly wind speed, wind direction, air temperature and cloud cover data from the Beijing Capital International Airport Meteorology Observatory, which is located $\sim 20 \mathrm{~km}$ north-east of the Fourth Ring Road (Fig. 1). The input meteorology is processed by the model to calculate parameters that determine the stability and height of the planetary boundary layer (PBL) for each hour. Cloud cover measurements, along with the time of day and day of year, are used to calculate incoming solar radiation which generates surface sensible heat flux $\left(F_{\theta 0}\right)$, friction velocity $\left(U_{*}\right)$ and Monin-Obukhov length $\left(L_{\mathrm{MO}}\right)$ terms via the surface energy balance. $L_{\mathrm{MO}}$ is a measure of the relative importance of me- chanical turbulence and buoyancy in the PBL and along with surface heat flux terms determines PBL height (PBLH) in the model. Alternatively, measurements of PBLH can be used if available. For this study, simulations are performed using directly input observations of mixed layer height (MLH) derived from ceilometer measurements taken at the IAP field site during the APHH-China campaign (Kotthaus and Grimmond, 2018; Shi et al., 2019). The MLH represents the height of the lowest atmospheric layer always in direct contact with the earth's surface resulting from turbulent exchange (Kotthaus and Grimmond, 2018) and is assumed here to equate to the model's PBLH output.

ADMS-Urban calculates the ratio of PBLH to $L_{\mathrm{MO}}$, a measure of the relative importance of mechanical turbulence and buoyancy, to generate a continuous PBL stability profile that varies with height. This $\mathrm{PBLH} / L_{\mathrm{MO}}$ parameterisation controls the vertical and horizontal spread extents of each emitted Gaussian plume, with the aggregate contribution from each individual emission source determining hourly simulated pollutant concentrations. In unstable conditions, an additional convectively driven turbulence component is calculated. This produces a skewed, non-Gaussian concentration distribution, meaning that for elevated sources the height of maximum concentration and mean height of the plume itself will descend and ascend, respectively (CERC, 2017).

Differences between conditions at the exposed airport meteorological site and the predominantly built-up modelling domain, largely caused by frictional effects of buildings and street canyons that perturb near-surface dynamics locally, are accounted for through distinct definitions of surface roughness $\left(Z_{0}\right)$ and minimum Monin-Obukhov $L_{\mathrm{MO}}$ in both environments. $Z_{0}$ and minimum $L_{\mathrm{MO}}$ values of 0.5 and $30 \mathrm{~m}$, respectively, represent conditions at the meteorological measurement site. However, greater $Z_{0}$ and minimum $L_{\mathrm{MO}}$ values of 1.5 and $100 \mathrm{~m}$, respectively, typical of urban areas dominated by densely packed tall buildings and concrete surfaces (Stewart and Oke, 2012), are used across the modelling domain and displace the upwind vertical wind speed, wind direction and turbulence profiles derived from the meteorological measurements.

\subsubsection{PBL stability adjustment}

Both $Z_{0}$ and minimum $L_{\mathrm{MO}}$ definitions prevent the modelled boundary layer from becoming unrealistically stable in urban areas where the surface radiation balance is perturbed by a number of factors, including anthropogenic heat release, building geometry and the thermal properties of concrete surfaces (Oke, 1982). The resulting positive temperature differential between urban areas and the surrounding rural environment is referred to as the UHI effect (Hamilton et al., 2014). This phenomenon is strongest in the late afternoon and early evening hours, when anthropogenic heat from rush hour traffic and residential heating systems, as well as incoming solar 


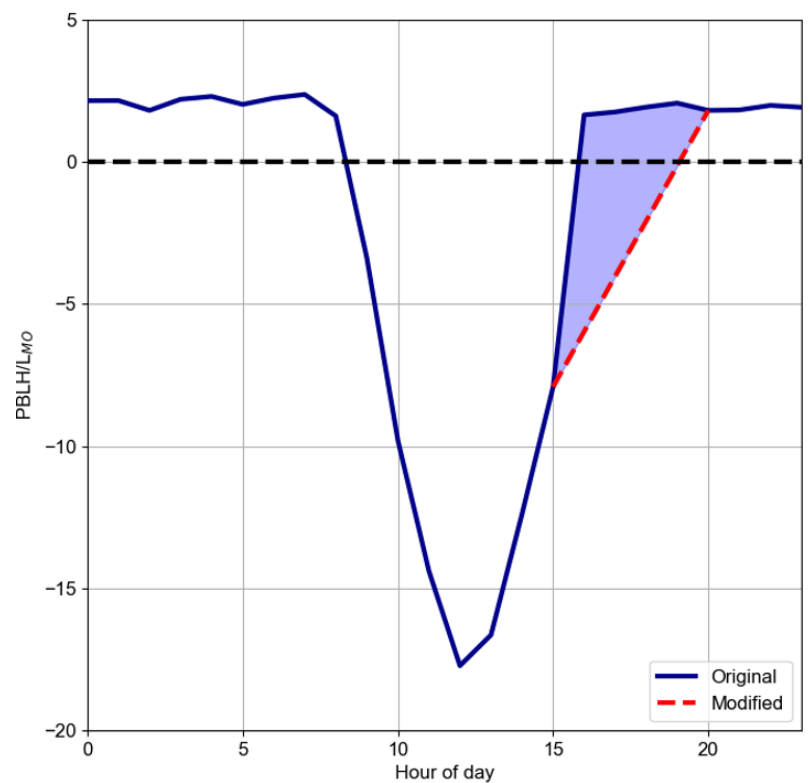

Figure 2. Diurnal mean PBLH $/ L_{\mathrm{MO}}$ values for the campaign period (blue line). Modified PBLH $/ L_{\mathrm{MO}}$, from 16:00 to 19:00, to account for evening UHI, shown by red dashed line.

radiation stored in the urban fabric throughout the day, is released into a stabilising PBL (Liu et al., 2007).

For this study, a further restriction on PBL stability has been applied to more comprehensively account for Beijing's strong evening UHI (K. Wang et al., 2017). Figure 2 shows how the PBL stability, represented by $\mathrm{PBLH} / L_{\mathrm{MO}}$, varies diurnally for the campaign period. The $L_{\mathrm{MO}}$ values are derived from a prior model simulation without stability modifications and the observed MLH (Sect. 2.2.1) is used as the PBLH. PBLH $/ L_{\mathrm{MO}}>1,-0.3 \leq \mathrm{PBLH} / L_{\mathrm{MO}} \leq 1$ and $\mathrm{PBLH} / L_{\mathrm{MO}}<-0.3$ represent stable, neutral and unstable conditions, respectively.

During the day, the surface net radiation is partitioned between upwards fluxes of sensible and latent heat and the downwards flux of heat into the ground (Oke, 1982). The version of ADMS-Urban used here (v 4.2) assumes that this ground heat flux is a constant proportion of the net radiation. In reality, this proportion varies diurnally, peaking around midday when a greater proportion of incoming solar radiation is stored by the urban fabric (Anandakumar, 1999; Grimmond and Oke, 1999). The release of this excess heat in the early evening sustains convection in the PBL, prolonging its instability. To account for this, a constant rate of decrease in PBLH $/ L_{\mathrm{MO}}$ has been assumed between original modelled values for 15:00 and 20:00, producing the modified campaign period mean $\mathrm{PBLH} / L_{\mathrm{MO}}$ diurnal profile illustrated in Fig. 2. Modified $L_{\mathrm{MO}}$ values from 16:00 to 19:00 are added to the set of input meteorological variables for all subsequent simulations, with the directly input PBLH measurements remaining unchanged. This adjustment increases sen- sible and latent heat fluxes, therefore enhancing the turbulent mixing of air during this early evening period. The 16:0019:00 time window is chosen as it coincides with sunset in November-December in Beijing, and it is in agreement with the extended duration of evening sensible heat flux decay in urban areas, compared with surrounding rural areas, observed by other UHI-related studies (Zhou et al., 2013; Barlow et al., 2015). Without this adjustment, the model tends to predict overly stable meteorological conditions in the early evening, which can lead to the over-prediction of pollutant concentrations. It is important to note that the modelled surface heat flux and $L_{\mathrm{MO}}$ terms are calculated independently of the PBLH, so that small positive $L_{\mathrm{MO}}$ values can generate an overly stable boundary layer even when paired with the measured MLH assumed here to represent real-world stability conditions.

\subsubsection{Chemistry}

The chemical transformation of pollutants contained within each dispersing plume is represented using the GRS chemistry scheme (Malkin et al., 2016). Typically, regional CTMs such as WRF-Chem and CMAQ use detailed chemical mechanisms containing hundreds or even thousands of reactions involving $\mathrm{NO}, \mathrm{NO}_{2}, \mathrm{O}_{3}$ and VOCs, including homogeneous and heterogeneous aerosol production (Sarwar and Luecken, 2008). The GRS, however, simplifies these to the following seven reactions:

$$
\begin{aligned}
& \mathrm{ROC}+h v \rightarrow \mathrm{RP}+\mathrm{ROC}, \\
& \mathrm{RP}+\mathrm{NO} \rightarrow \mathrm{NO}_{2}, \\
& \mathrm{NO}_{2}+h v \rightarrow \mathrm{NO}+\mathrm{O}_{3}, \\
& \mathrm{NO}+\mathrm{O}_{3} \rightarrow \mathrm{NO}_{2}, \\
& \mathrm{RP}+\mathrm{RP} \rightarrow \mathrm{RP}, \\
& \mathrm{RP}+\mathrm{NO}_{2} \rightarrow \mathrm{SGN}, \\
& \mathrm{RP}+\mathrm{NO}_{2} \rightarrow \mathrm{SNGN},
\end{aligned}
$$

where ROC represents reactive organic compounds, RP is the radical pool, SGN is the stable gaseous nitrogen product and SNGN is the stable non-gaseous nitrogen product (CERC, 2017). The inclusion of fast $\mathrm{NO}_{x}-\mathrm{O}_{3}$ chemistry, whereby at high $\mathrm{NO}_{x}$ levels, $\mathrm{NO}$ consumes $\mathrm{O}_{3}$ (Reactions R3 and $\mathrm{R} 4$ ), enables the sharp pollutant species concentration increases, with proximity to major road or large point sources, to be captured. Reaction (R1) summarises all of the oxidation and photolysis reactions that lead to radical production from VOCs (Malkin et al., 2016), while Reactions (R2) and (R5) represent subsequent radical loss.

An additional set of reactions involves the production of ammonium sulfate, following the oxidation of $\mathrm{SO}_{2}$ and reactions with water and ammonia, and this provides a source of both $\mathrm{PM}_{10}$ and $\mathrm{PM}_{2.5}$. Other secondary organic and inorganic components of particulate matter, which can comprise up to a combined $70 \%$ of total $\mathrm{PM}_{2.5}$ mass in Beijing (Ma 
et al., 2017; Tao et al., 2017; Y. Wang et al., 2017), are accounted for in the background concentration field described in Sect. 2.1.4.

\subsubsection{Background pollutant concentrations}

Background pollutant concentrations represent the regional pollution levels on which the local emissions build. For this study, background levels for $\mathrm{NO}_{2}, \mathrm{O}_{3}, \mathrm{PM}_{2.5}, \mathrm{PM}_{10}, \mathrm{SO}_{2}$ and $\mathrm{CO}$ are derived directly from hourly air quality measurement data and are assumed to be uniform across the study domain. Measured concentrations at 12 national air quality monitoring stations, run by the China National Environmental Monitoring Center (CNEMC), the IAP field site and an additional site $60 \mathrm{~km}$ south-east of Beijing, situated in the built-up Guangyang district of Langfang in Hebei province, are used to estimate this background concentration field. The locations of these 14 sites are given in Table 1.

For particulate matter $\left(\mathrm{PM}_{2.5}\right.$ and $\left.\mathrm{PM}_{10}\right)$, an hourly upwind background concentration is derived based on wind direction with concentrations selected from sites $3\left(270-360^{\circ}\right)$, $10\left(0-90^{\circ}\right)$ and $14\left(90-270^{\circ}\right)$ located to the NW, NE and SE of urban Beijing, respectively. Particulates have near-surface lifetimes of days to weeks; therefore, concentrations in Beijing are heavily influenced by long-range transport (LRT) of both primary and secondary components originating in neighbouring industrial regions (Y. Wang et al., 2017; Cheng et al., 2019). The measured upwind concentration is expected to capture this transported background regional air. Gaseous species such as $\mathrm{NO}_{2}$ have a much shorter lifetime $(\sim 1 \mathrm{~d})$ and therefore a smaller regional contribution, with concentrations across urban areas dominated primarily by local traffic sources (Zhang et al., 2014). The $\mathrm{NO}_{2}$ concentrations at the upwind monitoring station were subsequently not deemed representative of the true background value owing to both this greater spatial variation and the proximity of the upwind monitoring stations to local emission sources. Instead, to approximate background values for gaseous species $\left(\mathrm{NO}_{2}, \mathrm{O}_{3}\right.$, $\mathrm{CO}$ and $\mathrm{SO}_{2}$ ), the hourly minimum concentration for each pollutant across the 12 network monitoring stations and the IAP field site is selected, yielding an approximation for the underlying conditions uninfluenced by local sources.

\subsection{Emissions inventory processing}

For this study, ADMS-Urban simulations use both aggregate 3-D grid source and explicit road source emissions of $\mathrm{NO}_{x}$, $\mathrm{NO}_{2}, \mathrm{SO}_{2}, \mathrm{VOC}$ (total), $\mathrm{PM}_{2.5}, \mathrm{PM}_{10}$ and $\mathrm{CO}$ derived from a standard and an optimised version of the high-resolution $(3 \mathrm{~km})$ MEIC v1.3 emissions inventory. The standard MEIC v1.3 emissions inventory, for 2013, consists of five emission source sectors: transportation, power, industrial, residential and agricultural (Qi et al., 2017). Note that the latter is not used in this study due to both the lack of farmland in urban Beijing and the negligible contributions to the pollutant species simulated in this study from agricultural emission sources (Qi et al., 2017). The transportation sector is estimated following Zheng et al. (2014), in which county-level emissions, derived from county-level vehicle ownership, are downscaled to grids based on road network and road-specific vehicle activity data. Liu et al. (2015) describe the unitbased technique, adopted to generate the power sector emissions, which utilises the Coal-fired Power Plant Emissions Database (CPED), including information on the technologies, activity data, operation situation, emission factors and locations of individual units. Industrial and residential sector emissions are calculated from provincial-level activity data and emission factors (Zheng et al., 2017). Industrial emissions are downscaled to the county level using GDP (National Bureau of Statistics, 2014), with both industry and residential emissions further distributed to grid-level resolutions based on high-resolution $(\sim 1 \mathrm{~km})$ population density data (Oak Ridge National Laboratory, 2013) (Zheng et al., 2017). To model conditions during the APHH-China winter campaign, the MEIC v1.3 emissions inventory is re-scaled for this study to account for the 2013-2016 emission reductions in Beijing (Sect. 1). According to Cheng et al. (2019), total emissions of $\mathrm{NO}_{x}$ (and $\left.\mathrm{NO}_{2}\right), \mathrm{SO}_{2}$, VOCs and $\mathrm{PM}\left(\mathrm{PM}_{2.5}\right.$ and $\mathrm{PM}_{10}$ ) in Beijing were estimated to decrease by $30 \%$, $63 \%, 27 \%, 35 \%$ and $30 \%$, respectively, between 2013 and 2016. This adjusted MEIC v1.3 emissions inventory is hereafter referred to as MEIC Std.

An alternate optimised version of MEIC v1.3 (hereafter referred to as MEIC Opt) was created (Li et al., 2018), for November and December 2016, with the aim of addressing the over-allocation of emissions to urban areas that occurs when downscaling MEIC v1.3 to fine scales based on proxy data (Zheng et al., 2017). This MEIC Opt inventory was created using the Nested Air Quality Prediction Modeling System (NAQPMS) to perform iterative minimisation of a cost function comparing NAQPMS simulations with winter campaign observations (Li et al., 2018). This optimisation algorithm was used to redistribute MEIC emissions from central urban Beijing to suburban and rural areas and to adjust their magnitude to represent the campaign period. Both the MEIC Std and MEIC Opt inventories comprise monthly varying emissions with distinct diurnal weighting profiles applied to each emission sector.

Aggregate 3-D grid sources contain the sum of all MEIC emission source sectors (residential, transportation, industrial and power) and consist of seven vertical layers (38, $90,152,228,337,480$ and $660 \mathrm{~m})$. In the absence of sufficient information required to model point source emissions (e.g. large power plants) explicitly, ADMS-Urban's 3-D grid sources enable plume release and dispersion from each of the seven grid source heights, accounting for tall emission sources included within the MEIC v1.3 power or industrial sector grids. MEIC Std and MEIC Opt campaign period mean $\mathrm{NO}_{2}, \mathrm{NO}_{x}, \mathrm{PM}_{2.5}, \mathrm{PM}_{10}, \mathrm{SO}_{2}$ and $\mathrm{VOC}$ emission rates 
Table 1. Locations (latitude and longitude) of all monitoring stations, including distinction between urban (within the Sixth Ring Road) and suburban site types. The approximate distance (nearest $10 \mathrm{~m}$ ) from each monitoring station to the nearest road centre line and the corresponding road type are also provided.

\begin{tabular}{|c|c|c|c|c|c|c|}
\hline & $\begin{array}{l}\text { Site } \\
\text { name }\end{array}$ & $\begin{array}{l}\text { Site } \\
\text { type }\end{array}$ & $\begin{array}{r}\text { Latitude } \\
\qquad\left({ }^{\circ} \mathrm{N}\right)\end{array}$ & $\begin{array}{r}\text { Longitude } \\
\left({ }^{\circ} \mathrm{E}\right)\end{array}$ & $\begin{array}{l}\text { Distance to nearest } \\
\text { road centre line }(\mathrm{m})\end{array}$ & $\begin{array}{l}\text { Nearest } \\
\text { road type }\end{array}$ \\
\hline 1 & Guanyuan & Urban & 39.93 & 116.34 & 90 & Secondary \\
\hline 2 & Wanshou Xigong & Urban & 39.88 & 116.35 & 80 & Tertiary \\
\hline 3 & Dingling & Suburban & 40.29 & 116.22 & 285 & Tertiary \\
\hline 4 & Dongsi & Urban & 39.93 & 116.42 & 200 & Secondary \\
\hline 5 & Tiantan & Urban & 39.89 & 116.41 & 90 & Tertiary \\
\hline 6 & Nongzhanguan & Urban & 39.94 & 116.46 & 400 & Trunk \\
\hline 7 & Haidan Wanliu & Urban & 39.99 & 116.29 & 100 & Tertiary \\
\hline 8 & Gucheng & Urban & 39.91 & 116.18 & 260 & Tertiary \\
\hline 9 & Shunyicheng & Suburban & 40.13 & 116.66 & 190 & Secondary \\
\hline 10 & Huairouzhen & Suburban & 40.33 & 116.63 & NA & Tertiary \\
\hline 11 & Changpingzhen & Suburban & 40.22 & 116.23 & 200 & Secondary \\
\hline 12 & Aoti Zhongxin (Olympic Park) & Urban & 39.98 & 116.4 & 110 & Secondary \\
\hline 13 & IAP & Urban & 39.97 & 116.37 & 110 & Secondary \\
\hline 14 & TCM Medical Material Company & Urban & 39.52 & 116.69 & NA & Secondary \\
\hline
\end{tabular}

NA - not available

from 3-D grid sources, aggregated across all, urban and suburban grid cells, are shown in Table 2.

An explicit network of road emissions for Beijing has been constructed based on the MEIC transportation sector emissions. Figure 3 illustrates the pseudo top-down approach adopted here in the absence of detailed information on traffic activity and fleet composition. Figure 3a shows the spatial distribution of the November and December mean MEIC Std transportation sector surface $\mathrm{NO}_{2}$ emissions. The transportation sector emissions of all pollutants are apportioned to individual road segments on a grid cell-by-grid cell basis, using the ArcGIS geographic information system software. The spatial road network of Beijing, presented in Fig. 3b, is provided by the OpenStreetMap dataset (https://openstreetmap.org/, last access: 6 June 2019) and includes individual road segment type and geometry information. Emissions are mapped onto the road network based on each road segment length and an emissions weighting factor, producing the distribution shown in Fig. $3 \mathrm{c}$, following Eq. (1):

$\operatorname{Emis}_{i, j, k}=\frac{l_{i, j} \cdot w_{k}}{\sum_{i=1}^{n}\left(l_{i, j} \cdot w_{k}\right)} \times E_{j}$,

where $l_{i, j}$ represents the length of road segment $i$ in grid cell $j$ of road type $k$. The weighting factor of road type $k$ is given by $w_{k} . E_{j}$ and $n$ denote the total traffic emissions and number of road segments in grid cell $j$, respectively. A weighted mean emission rate, based on road segment length, is calculated along segments traversing multiple grid cells in order to avoid discontinuities.
Weighting factors (Table 3) are estimated using road type and width (based on manual inspection of the most frequent number of lanes for each road type), acting as proxies for traffic activity. Each road type weighting factor is applied equally to all pollutant species. The magnitude of weighting factors relative to each other is important, rather than their absolute values, according to Eq. (1). Minor roads were removed from the network to limit the computational expense of each simulation and are instead aggregated within the 3D grid sources. This methodology is based on the assumption that traffic volume, speed and fleet composition are constant across all road type classes listed in Table 3. However, substantial variations in traffic flow characteristics on roads of the same classification within Beijing's urban area have been observed. For example, Jing et al. (2016) used GPSfitted buses and taxis to collect near real-time traffic data along the major road types in Beijing, finding much greater levels of congestion closer to the urban centre, causing increased traffic volume and vehicle speed variations. Additionally, Y. Zhang et al. (2018) observed a greater proportion of vehicles with lower emission standards on roads outside the Fifth Ring Road. Given that the same emission weighting factors for roads of the same class are applied across the domain and the lack of traffic flow variations on specific roads within cities in the MEIC framework (Zheng et al., 2014), the methodology adopted here may under-allocate emissions on more congested inner-city roads and over-allocate emissions in suburban areas.

\subsection{Model evaluation}

Evaluation of regional-scale Eulerian CTMs involves the comparison of measurements at specific monitoring site loca- 
Table 2. Campaign period mean MEIC Std (S) and MEIC Opt $(\mathrm{O})$ pollutant species emissions $\left(\mathrm{t} \mathrm{d}^{-1}\right)$ aggregated across all, urban and suburban grid cells. Change $(\%)$ in emissions between inventories, following optimisation, calculated as $(\mathrm{O}-\mathrm{S} / \mathrm{S}) \times 100$.

\begin{tabular}{|c|c|c|c|c|c|c|}
\hline \multicolumn{7}{|c|}{ Campaign period mean aggregate pollutant emission rates $\left(\mathrm{td}^{-1}\right)$} \\
\hline \multirow[t]{2}{*}{ Region of domain } & $\mathrm{NO}_{2}$ & $\mathrm{NO}_{x}$ & $\mathrm{PM}_{2.5}$ & $\mathrm{PM}_{10}$ & $\mathrm{SO}_{2}$ & VOC \\
\hline & $\mathrm{O}$ & $\mathrm{O}$ & $\mathrm{O}$ & $\mathrm{O}$ & $\mathrm{O}$ & $\mathrm{O}$ \\
\hline All & $60.2 \quad 46.9$ & $889.3 \quad 504.6$ & $86.2 \quad 110.3$ & $156.5 \quad 176.1$ & $72.5 \quad 54.4$ & $\begin{array}{ll}717.6 & 1942.5\end{array}$ \\
\hline Change (\%) & -22.1 & -43.3 & 28.0 & 12.5 & -25.0 & 170.7 \\
\hline Urban & $44.0 \quad 22.1$ & $649.1 \quad 238.3$ & $49.9 \quad 46.9$ & $89.3 \quad 69.5$ & $42.4 \quad 27.5$ & $476.8 \quad 1273.1$ \\
\hline Change (\%) & -49.8 & -63.3 & -6.0 & -22.2 & -35.1 & 167.0 \\
\hline Suburban & $16.3 \quad 24.7$ & $240.2 \quad 266.2$ & $36.3 \quad 63.4$ & $67.2 \quad 106.7$ & $30.1 \quad 27.0$ & $240.8 \quad 669.4$ \\
\hline Change (\%) & 51.5 & 10.8 & 74.7 & 58.8 & -10.3 & 178.0 \\
\hline
\end{tabular}
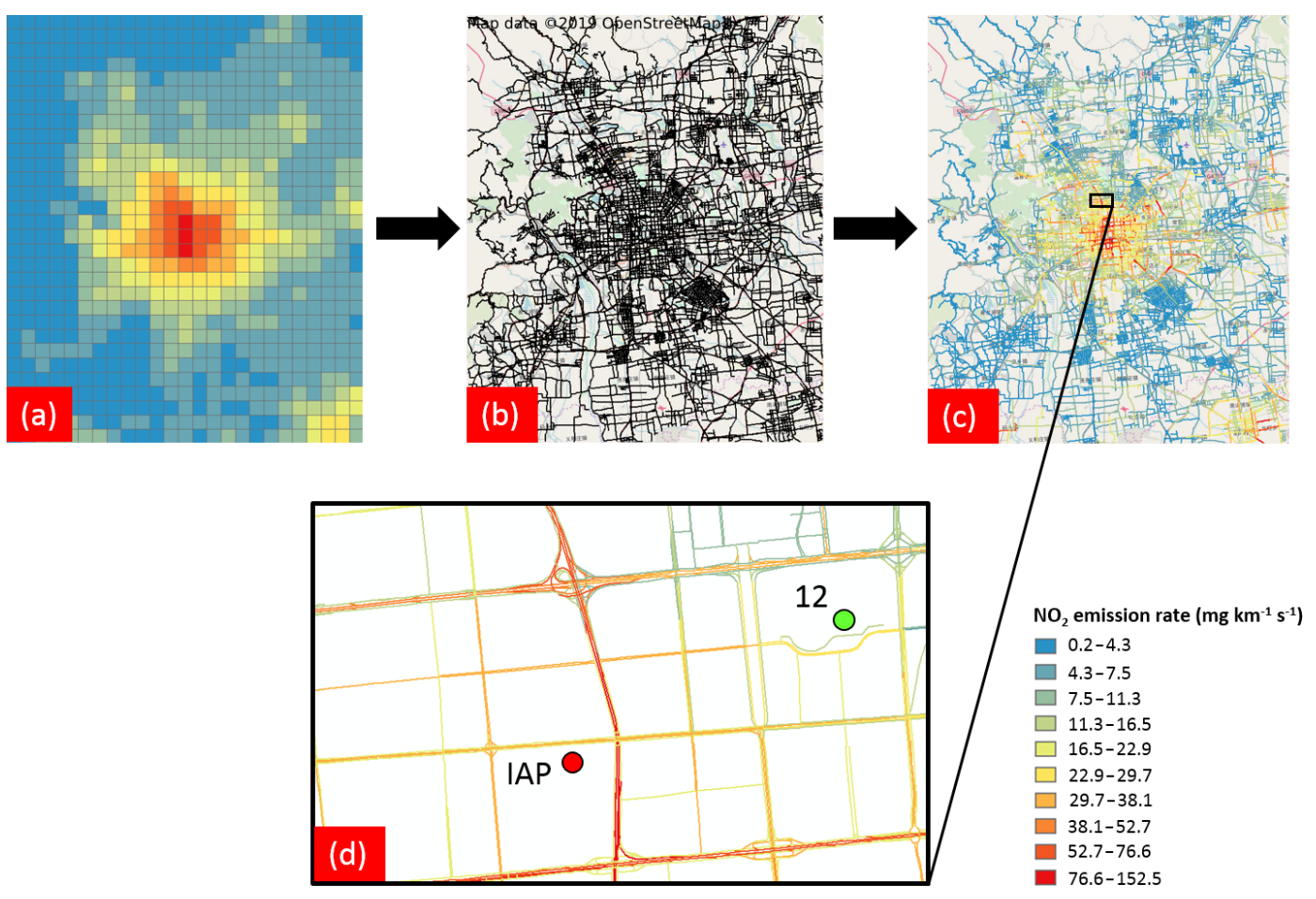

Figure 3. (a) Spatial distribution of November and December mean transportation sector MEIC Std $\mathrm{NO}_{2}$ emissions (lowest vertical layer) covering the full study domain, (b) spatial road network of Beijing (source: OpenStreetMap, () OpenStreetMap contributors 2019. Distributed under a Creative Commons BY-SA License), (c) explicit road source $\mathrm{NO}_{2}$ emission rates following apportioning of (a) onto (b), and (d) enlarged section of the road emissions network covering the IAP field site and site 12.

Table 3. Estimated emission weighting factors for each modelled road type.

\begin{tabular}{lr}
\hline Road type & Weighting \\
\hline Motorway & 0.7 \\
Trunk & 0.5 \\
Primary & 0.4 \\
Secondary & 0.25 \\
Tertiary & 0.15 \\
\hline
\end{tabular}

tions with simulated concentrations in the nearest model grid box (Zhong et al., 2016; Y. Wang et al., 2017; Zheng et al., 2017). However, for street-scale air quality modelling with ADMS-Urban, pollutant concentrations can be simulated at specific locations, referred to hereafter as receptor points. For this study, concentrations are modelled at the locations of the 12 monitoring network stations, as well as the IAP field site, for direct comparison with the corresponding measured concentrations. The following three statistical performance measures are considered simultaneously, enabling a comprehensive evaluation of modelled predictions of concentrations, 
using both MEIC Std and MEIC Opt emissions inventories, during the APHH-China winter campaign period.

normalised mean square error (NMSE) $=\frac{\overline{(M-O)}^{2}}{\overline{M O}}$,

fractional bias $(\mathrm{Fb})=\frac{\bar{M}-\bar{O}}{0.5(\bar{O}+\bar{M})}$,

Pearson's correlation coefficient $(R)=$

$$
\frac{1}{n-1} \sum_{i=1}^{n}\left(M_{i}-\bar{M} / \sigma_{M}\right)\left(O_{i}-\bar{O} / \sigma_{O}\right)
$$

where $n$ denotes the total number of matching hourly modelled and observed concentrations; $\bar{M}$ and $\bar{O}$ indicate mean modelled and observed concentrations, respectively, and $\sigma$ is the standard deviation.

NMSE (ideal value $=0$ ) is a measure of the model's overall accuracy (Cai and Xie, 2011), incorporating the effects of both systematic and random errors (Patryl and Galeriu, 2011); Fb (ideal value $=0$ ) reflects the model's tendency to overestimate or underestimate concentrations, compared to measurements; and $R$ (ideal value $=1$ ) informs on the extent to which modelled and measured values are linearly related.

In this study, the statistical evaluation of pollutant concentrations simulated at the exact coordinates of the measurement locations is complemented by street-scale-resolution maps which more clearly illustrate the strong spatial heterogeneity of pollution levels across Beijing. Fully resolved $\mathrm{PM}_{2.5}, \mathrm{NO}_{2}$ and $\mathrm{O}_{3}$ concentration fields in central Beijing are simulated with a combination of regularly spaced receptor points at $\sim 150 \mathrm{~m}$ and additional output points distributed within and in the immediate vicinity of all individual road emission source segments. The addition of emission source-oriented output points increases the model resolution to $<10 \mathrm{~m}$ across regions containing dense distributions of explicit road sources, therefore enabling the sharp pollutant concentration variations adjacent to roads to be captured.

\section{Results and discussion}

Street-scale-resolution maps of $\mathrm{PM}_{2.5}, \mathrm{NO}_{2}$ and $\mathrm{O}_{3}$ concentrations across a region of urban Beijing are presented in Sect. 3.1. Section 3.2 provides a statistical evaluation of simulated pollutant species against hourly measurements at 12 monitoring network sites and the IAP campaign field site (Table 1), using both MEIC Std and MEIC Opt inventories. Diurnal cycles of $\mathrm{NO}_{x}, \mathrm{NO}_{2}$ and $\mathrm{O}_{3}$ concentrations are given in Sect. 3.3, and Sect. 3.4 contains an analysis of local and regional $\mathrm{PM}_{2.5}$ sources. Sensitivity studies explore the impact on model performance of including explicit road emission sources, varying diurnal emissions profiles and accounting for the evening UHI in Sects. 3.5, 3.6 and 3.7, respectively.

\subsection{Street-scale variation of $\mathrm{PM}_{2.5}, \mathrm{NO}_{2}$ and $\mathrm{O}_{3}$ concentrations}

Mean $\mathrm{PM}_{2.5}, \mathrm{NO}_{2}$ and $\mathrm{O}_{3}$ concentrations simulated for the campaign period (5 November-10 December 2016), using the MEIC Opt inventory, for a region of urban Beijing within the Fifth Ring Road are presented in Fig. 4. The influence of the explicit road emissions network on the spatial variation of all species is clear, most notably along the Second, Third and Fourth Ring Roads. $\mathrm{PM}_{2.5}$ and $\mathrm{NO}_{2}$ concentrations peak at 125 and $160 \mu \mathrm{g} \mathrm{m}^{-3}$, respectively, along the ring road centre lines, before sharply decaying. The magnitudes of this drop and distance across which it occurs are determined not only by emission source strength, but also by physical and chemical mechanisms, with the speed of plume dispersion and mixing, controlled by mechanical and convective turbulence generation, interacting with the differing lifetimes of individual pollutants. In Fig. 5, mean $\mathrm{NO}_{2}$ concentrations decrease by $\sim 20-25 \mu \mathrm{g} \mathrm{m}^{-3}$ along a horizontal profile extending $100 \mathrm{~m}$ either side of the Second Ring Road. The spatial variation of $\mathrm{O}_{3}$ concentrations is approximately inversely related to these $\mathrm{NO}_{2}$ levels. Modelled $\mathrm{O}_{3}$ concentrations decrease to $5 \mu \mathrm{g} \mathrm{m}^{-3}$ along the Second Ring Road centre line and reach $25 \mu \mathrm{g} \mathrm{m}^{-3}$ between the Fourth and Fifth Ring Roads (Fig. 4). This is a result of the fast reaction of $\mathrm{O}_{3}$ with $\mathrm{NO}$ (titration) (Reaction R4) which dominates in high- $\mathrm{NO}_{x}$ environments (Y. Zhang et al., 2015; Tang et al., 2017; Ma et al., 2018), such as those next to major roads. The conversion of primary $\mathrm{NO}$ exhaust emissions to $\mathrm{NO}_{2}$, following the titration of $\mathrm{O}_{3}$, also produces a sharply increasing $\mathrm{NO}_{2} / \mathrm{NO}_{x}$ ratio with distance from the road centre (Fig. 5). In the following sections, a comprehensive evaluation of the model performance is presented.

\subsection{Model evaluation and assessment of emission inventories}

Table 4 summarises the performance of ADMS-Urban in Beijing during the APHH-China winter measurement campaign, with comparisons between MEIC Std and MEIC Opt simulations enabling an assessment of the MEIC v1.3 optimisation.

Modelled $\mathrm{NO}_{x}$ concentrations at the IAP field site display the most substantial differences between the two simulations (Table 4; Fig. 6). Modelled $\mathrm{NO}_{x}$ concentrations using the

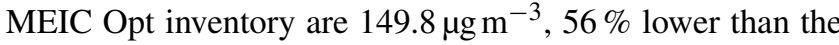
MEIC Std case, leading to NMSE and $\mathrm{Fb}$ decreases from 2.35 to 0.63 and 0.93 to 0.17 , respectively (Table 4 ). This enhanced model agreement is reflected in Fig. 6, in which a large proportion of modelled $\mathrm{NO}_{x}$ values reaching 400 $600 \mu \mathrm{g} \mathrm{m}^{-3}$ with MEIC Std, up to a factor of 6 higher than measurements, is reduced to within a factor of 2 of measured concentrations using MEIC Opt. This result reflects the $63 \% \mathrm{NO}_{x}$ emissions reduction across urban Beijing, over all source sectors, in the optimised inventory (Table 2). How- 

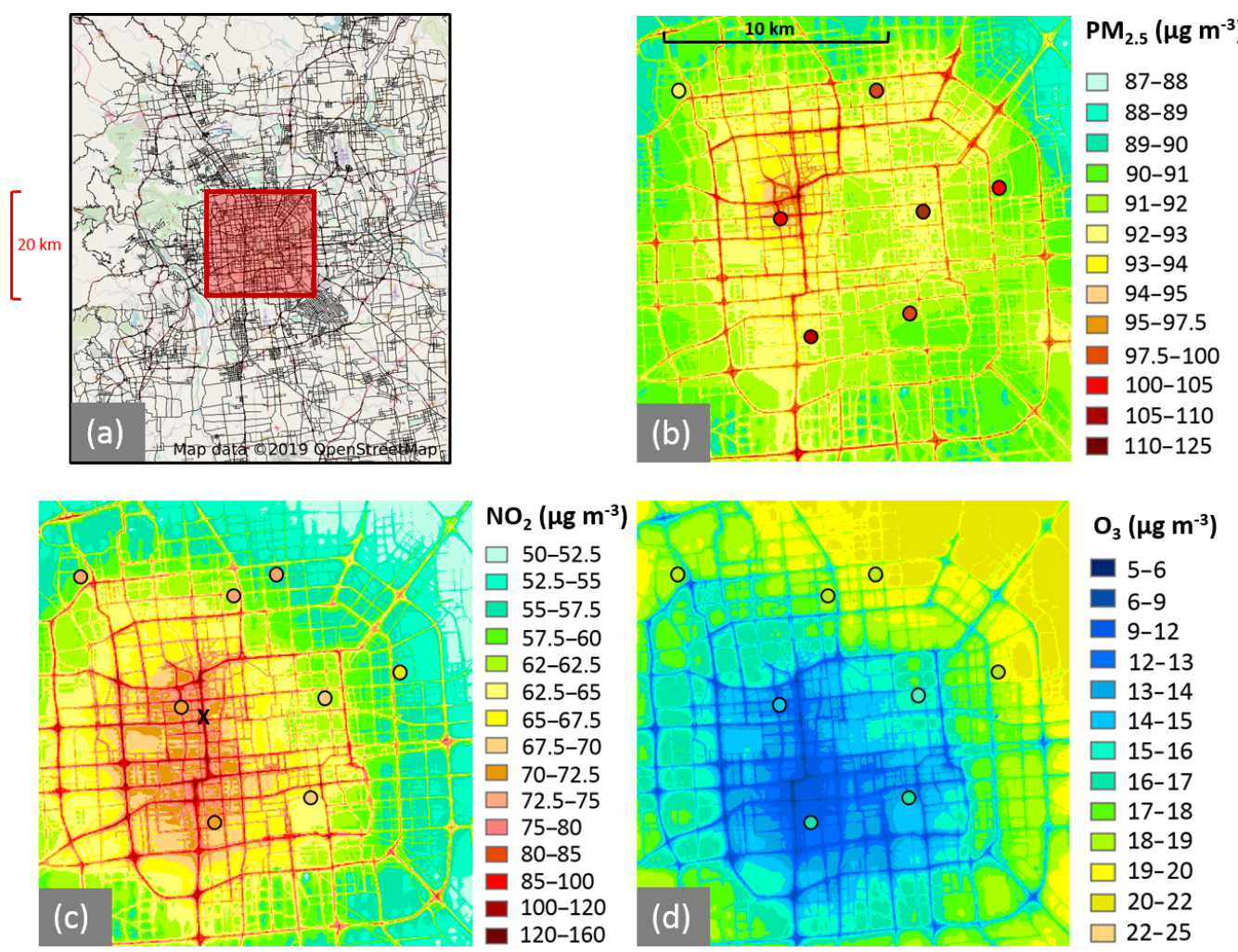

Figure 4. Spatial maps of mean $\mathrm{PM}_{2.5}$ (b), $\mathrm{NO}_{2}$ (c), and $\mathrm{O}_{3}$ (d) concentrations for the winter campaign period (5 November to 10 December 2016), simulated using the MEIC Opt emissions inventory. Simulated concentrations cover the region marked in (a). Mean measured concentrations at monitoring network sites $\left(\mathrm{NO}_{2}, \mathrm{O}_{3}\right.$ and $\left.\mathrm{PM}_{2.5}\right)$ and the IAP field site $\left(\mathrm{NO}_{2}\right.$ and $\left.\mathrm{O}_{3}\right)$ are represented by coloured dots. (C) OpenStreetMap contributors 2019. Distributed under a Creative Commons BY-SA License.

Table 4. Statistical evaluation of modelled pollutant concentrations for the campaign period, using MEIC Std (S) and MEIC Opt (O) emissions inventories. Mean modelled (Mod) and observed (Obs) concentrations and statistics divided into all (12 monitoring network sites and the IAP field site for $\mathrm{NO}_{2}$ and $\mathrm{O}_{3}$, monitoring network sites only for $\mathrm{PM}_{2.5}$ ) and urban and suburban monitoring site groups. Urban and suburban sites defined in Table $1 . \mathrm{NO}_{x}$ measurements only available at the IAP field site. Mean concentrations and statistics calculated from matching hourly values.

\begin{tabular}{|c|c|c|c|c|c|c|c|c|c|c|}
\hline & \multirow{2}{*}{\multicolumn{4}{|c|}{ Mean concentrations $\left(\mu \mathrm{g} \mathrm{m}^{-3}\right)$}} & \multicolumn{6}{|c|}{ Model evaluation statistics } \\
\hline & & & & & \multicolumn{2}{|c|}{ NMSE } & \multicolumn{2}{|c|}{$\mathrm{Fb}$} & \multicolumn{2}{|c|}{$R$} \\
\hline & Sites & $\operatorname{Mod}(\mathrm{S})$ & $\operatorname{Mod}(\mathrm{O})$ & Obs & $\mathrm{S}$ & $\mathrm{O}$ & $\mathrm{S}$ & $\mathrm{O}$ & $\mathrm{S}$ & $\mathrm{O}$ \\
\hline \multirow[t]{3}{*}{$\mathrm{PM}_{2.5}$} & All & 90.3 & 89.8 & 93.4 & 0.37 & 0.37 & -0.03 & -0.04 & 0.76 & 0.76 \\
\hline & Urb & 93.4 & 92.1 & 100.9 & 0.36 & 0.36 & -0.08 & -0.09 & 0.78 & 0.78 \\
\hline & Sub & 84.0 & 85.3 & 78.3 & 0.40 & 0.41 & 0.07 & 0.09 & 0.74 & 0.74 \\
\hline \multirow[t]{3}{*}{$\mathrm{O}_{3}$} & All & 10.4 & 14.6 & 18.5 & 1.54 & 0.74 & -0.56 & -0.24 & 0.71 & 0.79 \\
\hline & Urb & 6.1 & 12.8 & 17.2 & 3.20 & 0.93 & -0.95 & -0.29 & 0.70 & 0.77 \\
\hline & Sub & 20.0 & 18.6 & 21.4 & 0.48 & 0.47 & -0.07 & -0.14 & 0.82 & 0.83 \\
\hline \multirow[t]{3}{*}{$\mathrm{NO}_{2}$} & All & 69.5 & 65.7 & 65.3 & 0.27 & 0.30 & 0.06 & 0.00 & 0.55 & 0.53 \\
\hline & Urb & 79.2 & 71.4 & 71.3 & 0.27 & 0.31 & 0.10 & 0.00 & 0.42 & 0.44 \\
\hline & Sub & 47.9 & 52.9 & 51.8 & 0.21 & 0.23 & -0.08 & 0.02 & 0.74 & 0.70 \\
\hline $\mathrm{NO}_{x}$ & IAP & 345.5 & 149.8 & 126.1 & 2.35 & 0.63 & 0.93 & 0.17 & 0.35 & 0.41 \\
\hline
\end{tabular}




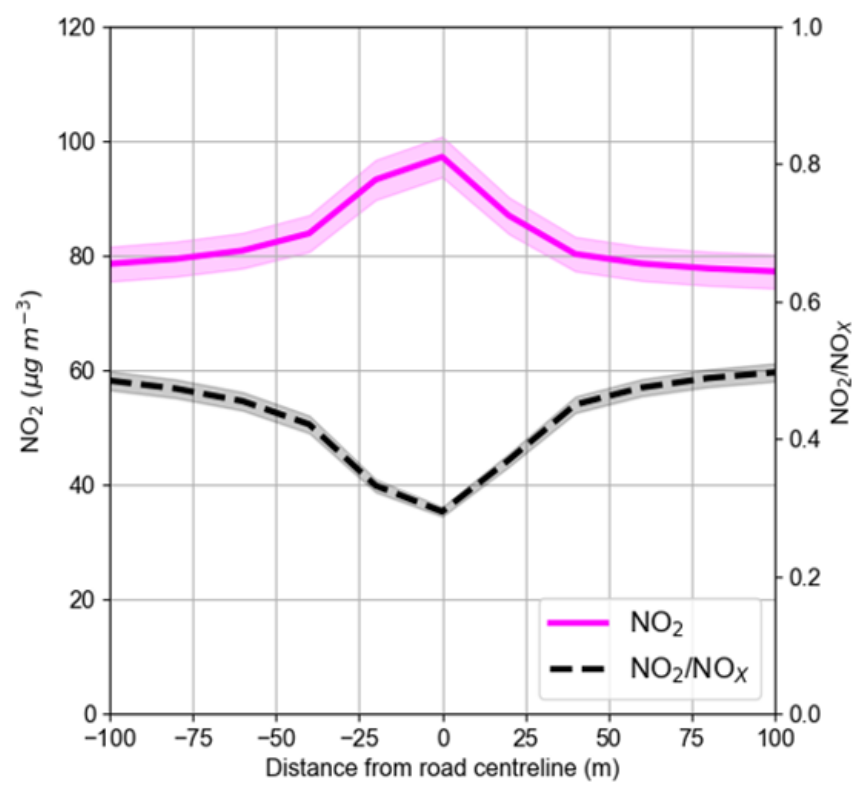

Figure 5. Simulated campaign period mean $\mathrm{NO}_{2}$ concentrations, with distance from the point on the Second Ring Road centre line (marked by $\mathrm{X}$ in Fig. 4c) using MEIC Opt (pink). Simulated $\mathrm{NO}_{2} / \mathrm{NO}_{x}$ ratio denoted by a black dashed line. Shaded areas represent the $95 \%$ confidence interval.

ever, correlation coefficient $(R)$ values for simulated $\mathrm{NO}_{x}$ remain low using both emissions inventories, slightly increasing from 0.35 to 0.41 with MEIC Opt. This smaller improvement in the correlation between measured and modelled $\mathrm{NO}_{x}$ using MEIC Opt, compared to NMSE and $\mathrm{Fb}$, reflects the dependency of $R$ on modelled $\mathrm{NO}_{x}$ levels that capture the correct temporal variation as well as the overall magnitude of $\mathrm{NO}_{x}$ measurements. The noise apparent in the measured and simulated $\mathrm{NO}_{x}$ comparison in Fig. 6 is therefore likely related to either the diurnal emissions profile or meteorological variations.

$\mathrm{NO}_{2}$ concentrations differ less, with NMSE values of 0.27 and 0.30 for the MEIC Std and MEIC Opt simulations, respectively. However, a greater difference is evident at urban receptor locations, with modelled $\mathrm{NO}_{2}$ concentrations from the MEIC Opt simulation $12 \%$ lower than those with MEIC Std. Across suburban sites, the opposite pattern is seen, with changes in $\mathrm{Fb}$ values between measurements and MEIC Std and MEIC Opt simulations ranging from negative $(-0.08)$ to positive (0.02), respectively. Both urban and suburban $\mathrm{NO}_{2}$ concentration changes, between simulations, reflect the overall redistribution of $\mathrm{NO}_{2}$ emissions in the MEIC Opt inventory, away from central Beijing and towards the city outskirts (Table 2).

The much greater urban $\mathrm{NO}_{x}$ concentration difference between the two simulations, as compared to $\mathrm{NO}_{2}$, can be attributed to two factors. Firstly, $\mathrm{NO}_{2}$ concentrations respond in a more non-linear way to $\mathrm{NO}_{x}$ emission changes than $\mathrm{NO}_{x}$ concentrations. This has been shown in previous stud- ies (e.g. Kurtenbach et al., 2012) and can be explained by the timescales and kinetics involved in the formation and destruction of secondary $\mathrm{NO}_{2}$. As $\mathrm{NO}_{x}$ levels decrease, the production of secondary $\mathrm{NO}_{2}$ via Reaction (R4) occurs faster as $\mathrm{O}_{3}$ concentrations are higher, leading to a slower rate of decrease of $\mathrm{NO}_{2}$ concentrations compared to $\mathrm{NO}_{x}$ emissions. Additionally, the proportion of $\mathrm{NO}_{x}$ directly emitted as $\mathrm{NO}_{2}$ is greater with MEIC Opt $\left(\mathrm{NO}_{2} / \mathrm{NO}_{x}=0.093\right)$ than MEIC Std $\left(\mathrm{NO}_{2} / \mathrm{NO}_{x}=0.068\right)$ (Table 2). This is reflected by the much greater reduction, from MEIC Std to MEIC Opt, in domain-aggregated $\mathrm{NO}_{x}$ emissions (43\%), as compared $\mathrm{NO}_{2}(22 \%)$ (Table 2).

At urban sites, $\mathrm{O}_{3}$ concentrations simulated with MEIC Opt are $12.8 \mu \mathrm{g} \mathrm{m}^{-3}$, which is a factor of 2 greater than those simulated using MEIC Std $\left(6.1 \mu \mathrm{g} \mathrm{m}^{-3}\right)$. Overall, the modelled $\mathrm{O}_{3}$ concentrations at urban sites using MEIC Opt are in closer agreement with the measurements, reflected by lower $\mathrm{Fb}$ and NMSE values of -0.29 and 0.93 , respectively, as compared to -0.95 and 3.2 in the MEIC Std simulations (Table 4). This is caused by both lower urban $\mathrm{NO}_{x}$ emissions in MEIC Opt and the reduced proportion of remaining $\mathrm{NO}_{x}$ emitted directly as NO, in MEIC Opt, leading to less $\mathrm{O}_{3}$ destruction through Reaction (R4). Contrastingly, higher MEIC Opt $\mathrm{NO}_{x}$ emissions in suburban Beijing reduce modelled $\mathrm{O}_{3}$ concentrations by $7 \%$. As a result, modelled $\mathrm{O}_{3}$ performance across all monitoring stations is substantially improved in the MEIC Opt simulation, with a NMSE reduction from 1.54 to 0.74 and an $R$ value increase from 0.71 to 0.79 (Table 4). These results highlight the strong dependency of $\mathrm{O}_{3}$ concentration predictions in urban areas, which inform human exposure analyses and influence future emission control implementation, on the accurate spatial variation and magnitude of $\mathrm{NO}_{x}$ emissions in high-resolution emissions inventories. The increase in modelled urban $\mathrm{O}_{3}$ concentrations following $\mathrm{NO}_{x}$ emissions reductions also highlights both the negative impact that controls on one pollutant species can have on another as well as the possible need for air quality guidelines that consider multiple pollutants, in contrast to the single pollutantbased air quality index used in China (Han et al., 2018).

Figure $7 \mathrm{a}$ and $\mathrm{b}$ illustrate site-specific differences between measured and simulated $\mathrm{NO}_{2}$ and $\mathrm{O}_{3}$ concentrations, respectively, using both emissions inventories. It is clear that, despite generally closer model agreement with measurements using MEIC Opt, $\mathrm{NO}_{2}$ concentrations remain substantially overestimated at urban sites $1\left(\sim 14 \mu \mathrm{g} \mathrm{m}^{-3}\right)$ and 2 $\left(\sim 9 \mu \mathrm{g} \mathrm{m}^{-3}\right)$. To help understand the cause of this, the sensitivity of modelled concentrations within $100 \mathrm{~m}$ of a road source near site 1 is illustrated in Fig. 8. Concentrations along a cross-road slice, extending $100 \mathrm{~m}$ either side of the road, are simulated after halving and doubling the magnitude of emissions of all species from this secondary road. Emissions from all other sources in the model configuration remain the same. Along the road centre, the range of simulated concentrations between emission scenarios is $\sim 10 \mu \mathrm{g} \mathrm{m}^{-3}$; however, this difference decreases to $\sim 2 \mu \mathrm{g} \mathrm{m}^{-3}$ at a distance 


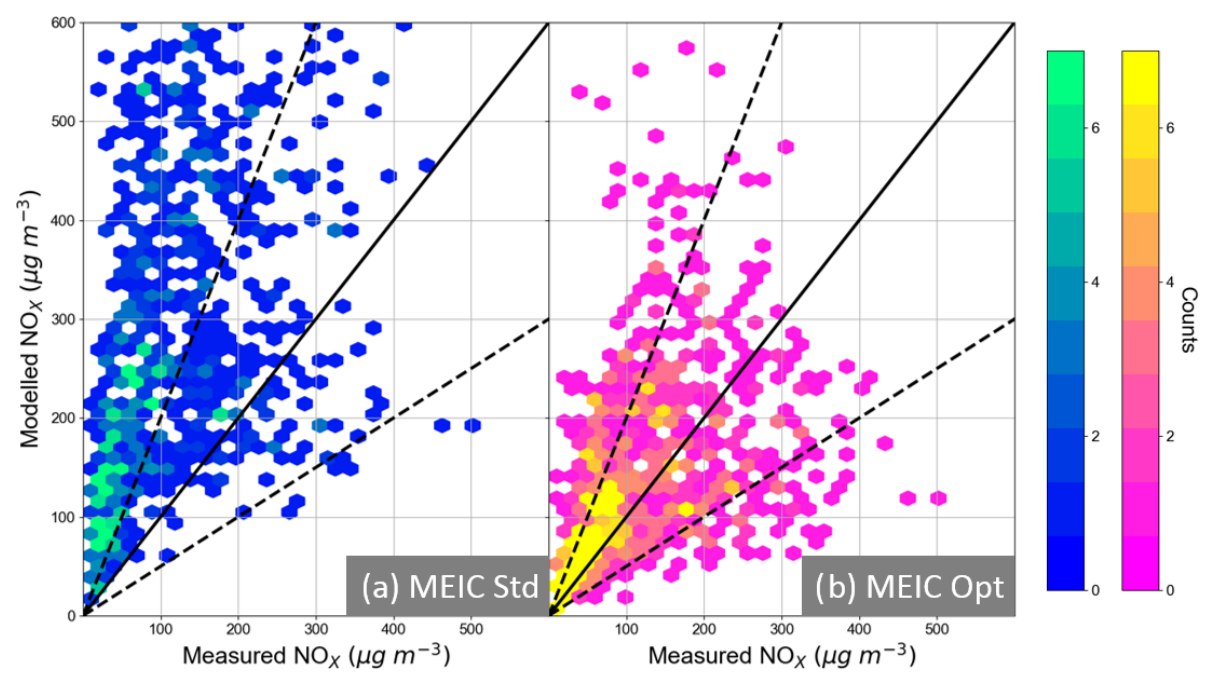

Figure 6. Hourly measured and modelled $\mathrm{NO}_{x}$ concentrations during the campaign period at the IAP field site. Panels (a) and (b) show concentrations simulated using MEIC Std and MEIC Opt, respectively. Colours represent the total number of matching hourly measured and modelled values contained within distinct hexagonal bins. Dashed lines mark a factor of 2 difference between measured and simulated concentrations.

of $100 \mathrm{~m}$, which is much lower than modelled $\mathrm{NO}_{2}$ overestimations produced by MEIC Opt at sites 1 and 2, each located $\sim 80-90 \mathrm{~m}$ from the nearest road. Therefore, the high modelled $\mathrm{NO}_{2}$ at sites 1 and 2 may only be partially attributed to an over-allocation of explicit road source emissions caused by either (a) underlying gridded emissions that are still too high or (b) not considering traffic volume/speed variations across the domain in road class emission weighting factor estimates. It should also be noted that the physical barriers to pollution dispersion represented by the urban canopy, and specifically street canyons, are not explicitly modelled in this study. This may lead to road emissions dispersing further from the road centre than in reality, therefore contributing to elevated modelled concentrations at greater distances from explicit road sources (Dédelé and Miskinyte, 2015). The sensitivity of the simulated $\mathrm{NO}_{2} / \mathrm{NO}_{x}$ concentration ratio to emission magnitude changes is also shown in Fig. 8. For each emissions scenario, the $\mathrm{NO}_{2} / \mathrm{NO}_{x}$ emissions ratio remains the same (0.093) (Table 2); however, the concentration ratio varies. With doubled $\mathrm{NO}_{x}$ emissions, the $\mathrm{NO}_{2} / \mathrm{NO}_{x}$ ratio is $\sim 0.3$ along the road centre, compared to $\sim 0.4$ with halved $\mathrm{NO}_{x}$ emissions (Fig. 8). This difference, which decays to zero at a distance of $\sim 75 \mathrm{~m}$, is mostly driven by PBL dynamics and the mixing of freshly emitted $\mathrm{NO}_{x}$ into air with a lower $\mathrm{NO}_{2} / \mathrm{NO}_{x}$ concentration ratio driven by the impact of higher $\mathrm{NO}_{x}$ emissions on secondary $\mathrm{NO}_{2}$ production via Reaction (R4), as discussed above.

A clear distinction exists between measured $\mathrm{PM}_{2.5}$ concentrations recorded at the suburban $\left(78 \mu \mathrm{g} \mathrm{m}^{-3}\right)$ and urban $\left(101 \mu \mathrm{g} \mathrm{m}^{-3}\right)$ monitoring stations (Table 4 ). These values are well in excess of China's annual $\mathrm{PM}_{2.5}$ National Ambient Air Quality Standard (NAAQS) of $35 \mu \mathrm{g} \mathrm{m}^{-3}$; however, con- centrations are expected to be higher in winter due to more stable meteorology (Zheng et al., 2015; Li et al., 2017) and enhanced coal combustion for residential heating and cooking and at power plants in neighbouring cities (Chen et al., 2017). Simulated $\mathrm{PM}_{2.5}$ concentrations, however, do not reflect such an urban-suburban discrepancy, with mean urban values exceeding those at suburban sites by only 9 and $7 \mu \mathrm{g} \mathrm{m}^{-3}$ using MEIC Std and MEIC Opt, respectively (Table 4). Across all monitoring stations, the range in campaign period mean measured concentrations is substantially higher $\left(\sim 40 \mu \mathrm{g} \mathrm{m}^{-3}\right)$ than the simulated range using both MEIC Std $\left(\sim 20 \mu \mathrm{g} \mathrm{m}^{-3}\right)$ and MEIC Opt $\left(\sim 15 \mu \mathrm{g} \mathrm{m}^{-3}\right)$, respectively. These results suggest that either $\mathrm{PM}_{2.5}$ emission sources are too uniform in magnitude and spatial distribution across the domain in the current model set-up or that the assumption of a homogeneous background $\mathrm{PM}_{2.5}$ concentration is invalid. It is likely that, by diluting $\mathrm{PM}_{2.5}$ emissions within individual grid cells and not explicitly representing point source emissions (e.g. large industrial units), the model is unable to capture the $\mathrm{PM}_{2.5}$ concentration hotspots that would increase the urban $\mathrm{PM}_{2.5}$-level increment and improve model agreement with the observed spatial variation. With the exception of simulated $\mathrm{PM}_{2.5}$ adjacent to major roads, this modelled uniformity in urban $\mathrm{PM}_{2.5}$ is clearly evident in Fig. 4, in which $\mathrm{PM}_{2.5}$ concentrations vary by only $\sim 5-10 \mu \mathrm{g} \mathrm{m}^{-3}$ across the area enclosed by the Fifth Ring Road. The mean estimated $\mathrm{PM}_{2.5}$ background concentration is $79 \mu \mathrm{g} \mathrm{m}^{-3}$ (Fig. 7), which is higher than both the mean measured concentrations at suburban sites 3 and 10, located to the north. This implies that either the background $\mathrm{PM}_{2.5}$ level is, in reality, inhomogeneous with lower concentrations to the north and higher to the south of urban Beijing or that 

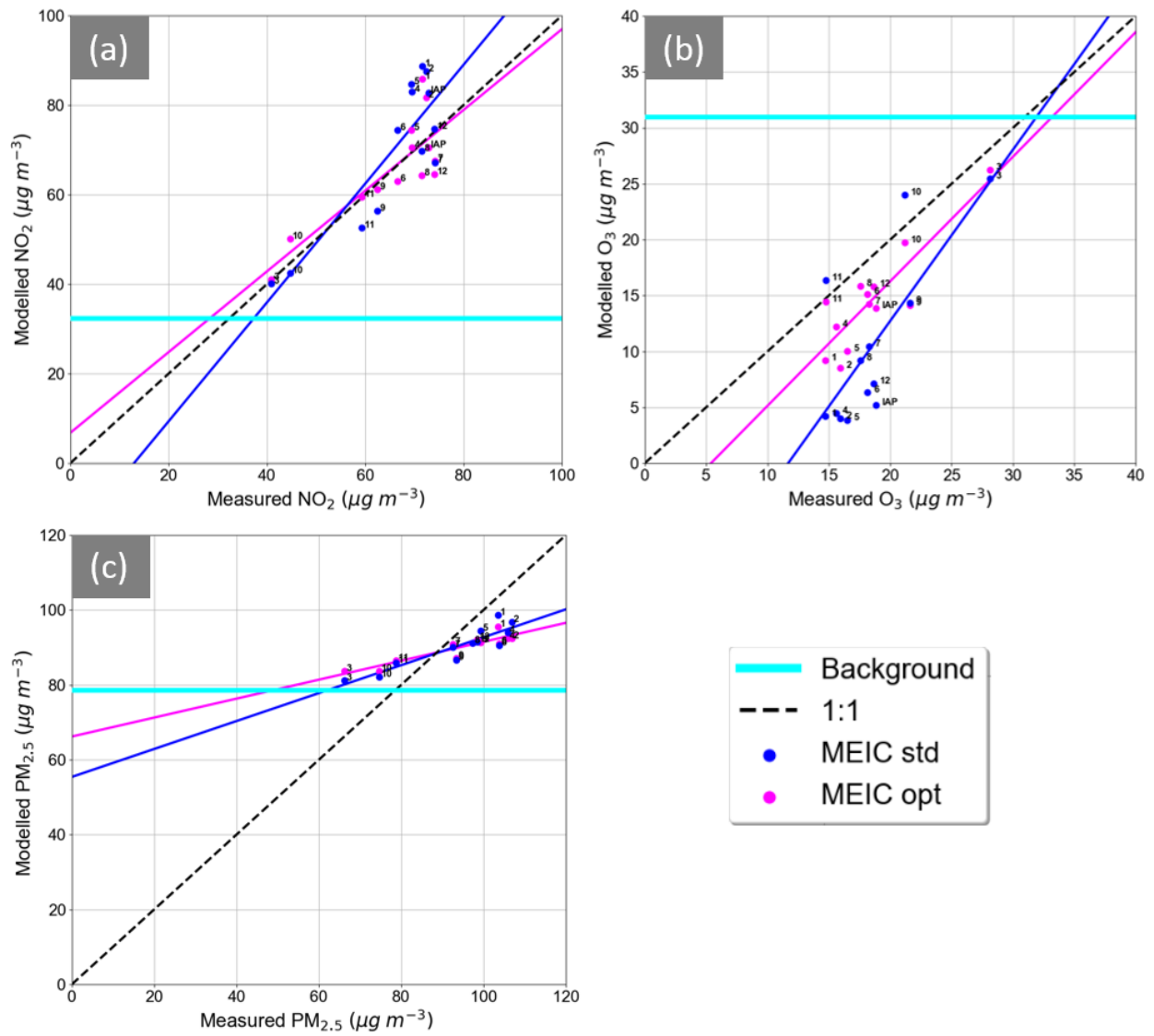

Figure 7. Campaign period mean measured and modelled (a) $\mathrm{NO}_{2}$, (b) $\mathrm{O}_{3}$, and (c) $\mathrm{PM}_{2.5}$ concentrations at all monitoring network sites (numbered) and the IAP field site $\left(\mathrm{NO}_{2}\right.$ and $\left.\mathrm{O}_{3}\right)$. Blue and pink lines indicate concentrations simulated using MEIC Std and MEIC Opt, respectively. Horizontal light blue line represents campaign period mean background concentrations calculated from measurements.
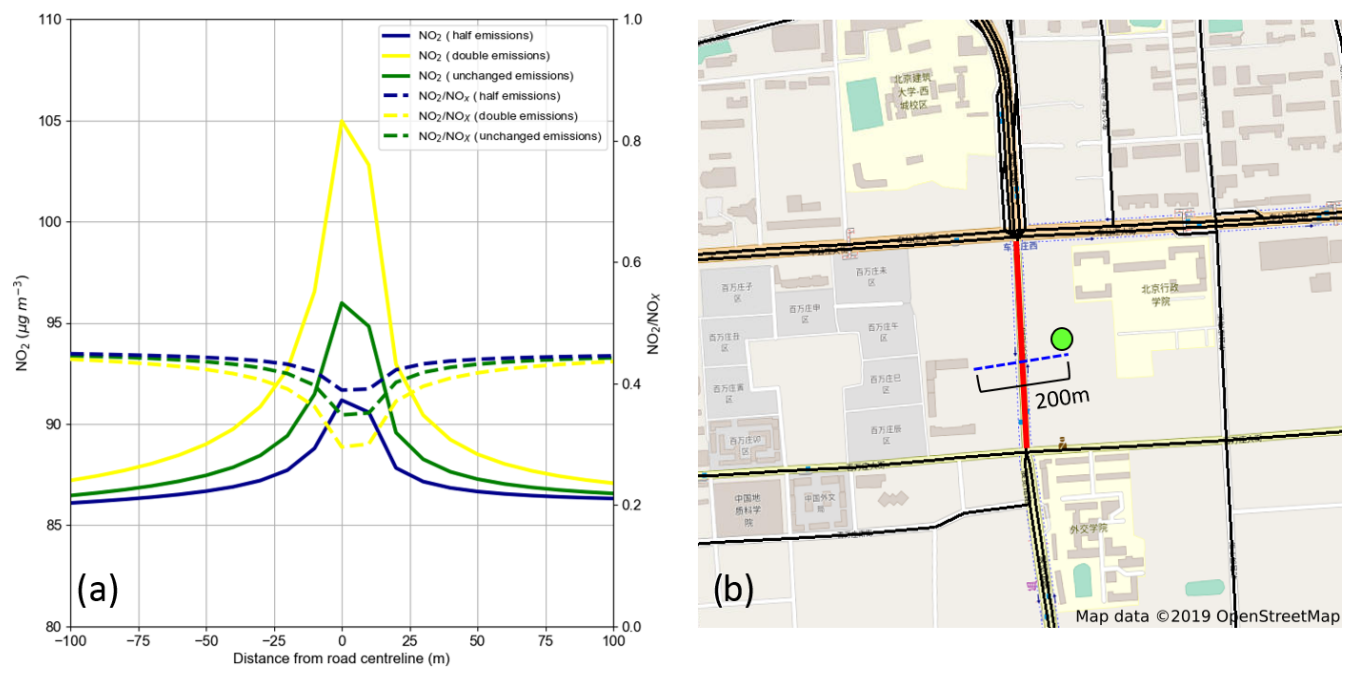

Figure 8. (a) Campaign period mean simulated $\mathrm{NO}_{2}$ concentrations and $\mathrm{NO}_{2} / \mathrm{NO}_{x}$ concentration ratios with distance from the road centre along the cross-road slice marked in (b) using half (blue), double (yellow) and unchanged (green) emissions of all species from an explicit road source marked by red line. The green circle in (b) marks the position of monitoring site 1. (b) (C) OpenStreetMap contributors 2019. Distributed under a Creative Commons BY-SA License. 
the upwind background monitoring site to the south is too heavily influenced by local emission sources and is not representative of background conditions. The relative contributions from $\mathrm{PM}_{2.5}$ emission sources and background inhomogeneity to the underestimated spatial variation in $\mathrm{PM}_{2.5}$ is further discussed in Sect. 3.4.

\subsection{Winter campaign diurnal cycles of $\mathrm{NO}_{2}, \mathrm{O}_{3}$ and $\mathrm{NO}_{x}$}

The diurnal variation of pollutant species in urban areas provides insight into how concentrations are impacted by both diurnal variations in meteorology and temporally varying emissions. The locations of urban stations 1, 12 and IAP, and suburban site 11 are illustrated in Fig. 9, with measured mean diurnal $\mathrm{NO}_{2}$ concentrations averaged over the campaign period at all four sites compared with those simulated using both the MEIC Std and MEIC Opt inventories in Fig. 10. There are several common differences between modelled and measured concentration profiles at all three urban stations (Fig. 10a, c and d). Firstly, both simulated $\mathrm{NO}_{2}$ diurnal cycles at sites 1,12 and IAP are considerably lower than measurements from 23:00 to 06:00. This discrepancy peaks at 02:00, with simulated concentrations $\sim 20$ and $\sim 30 \mu \mathrm{g} \mathrm{m}^{-3}$ lower than measurements, using MEIC Std and MEIC Opt, respectively. Observed $\mathrm{NO}_{2}$ concentrations at urban sites remain elevated between 23:00 and 06:00, relative to the rest of the day, resulting in a diurnal profile absent of the distinct morning and evening peaks commonly observed in other megacities, such as London (Hood et al., 2018). High nocturnal $\mathrm{NO}_{2}$ concentration measurements during the APHH-China winter campaign at the IAP field site are also noted by Shi et al. (2019).

Previous studies have attributed the evening influx of heavy duty diesel trucks (HDDTs), banned from commuting within the Fourth Ring Road from 06:00 to 23:00 (Zhang et al., 2019), to evening $\mathrm{NO}_{x}$ concentration increases across urban Beijing of up to $10 \mu \mathrm{g} \mathrm{m}^{-3}$ (Wu et al., 2016; Yang et al., 2019). A large proportion of this HDDT fleet originates in other provinces where emission standards are not as strict as those in Beijing (Wang et al., 2011). It is possible, therefore, that in a proxy-based emissions inventory (e.g. MEIC), such traffic restrictions and inter-provincial vehicle mobility are not fully accounted for (Zheng et al., 2014). This is supported by the much closer agreement between evening modelled and measured $\mathrm{NO}_{2}$ at suburban site 11 (Fig. 10b), situated outside the Sixth Ring Road (Fig. 9) and away from the influence of additional nighttime $\mathrm{HDDT}_{\mathrm{NO}}$ emissions. Additionally, ADMS-Urban makes an approximation when modelling dispersion in calm conditions by applying a minimum wind speed of $0.75 \mathrm{~m} \mathrm{~s}^{-1}$ (CERC, 2017). These stable, low wind speed conditions, however, are common in winter in Beijing and have been strongly linked to the acceleration of pollution accumulation during severe winter haze events (X. Zhang et al., 2015; Z. Zhang et al., 2016; L. Zhang et al., 2018). Therefore, it is likely that the large early morning $\mathrm{NO}_{2}$ concentration model underestimations across all three urban sites are a consequence of $\mathrm{NO}_{x}$ emissions that are too low in magnitude, from 23:00 to 06:00, dispersing into a simulated PBL that may be insufficiently stable due to the use of a minimum wind speed in the model.

From 06:00 to 09:00, modelled $\mathrm{NO}_{2}$ concentrations in both the MEIC Std and MEIC Opt simulations increase sharply (Fig. 10). This is most prominent at site 1 , where simulated levels approximately double during this $3 \mathrm{~h}$ period. This increase corresponds to the release of rush hour traffic-related $\mathrm{NO}_{x}$ emissions into a stable and shallow morning PBL. Contrastingly, measurements at these sites decline over this early morning period following an evening concentration peak as described above. This overestimation of $\mathrm{NO}_{2}$ continues throughout the afternoon, with similar profiles at sites 12 and IAP reflecting the close proximity of both receptor locations ( $\sim 3 \mathrm{~km}$ apart) (Fig. 9).

The concurrence of evening rush hour traffic emissions and a stabilising PBL, associated with the reduction in surface heating following sunset, creates a second simulated $\mathrm{NO}_{2}$ concentration peak at $\sim$ 18:00. In contrast to the simulated morning concentration rise, the close agreement between the measured and modelled times of onset and magnitude of this early evening increment indicates that the simulated stability adjustment (Sect. 2.1.2), implemented between 16:00 and 19:00, has successfully accounted for the re-release of stored heat, characteristic of large urban areas.

There is little difference between the diurnal $\mathrm{NO}_{2}$ concentration profiles simulated using the MEIC Std and MEIC Opt inventories, and this is consistent with the model evaluation results described in Sect. 3.2. Simulated $\mathrm{NO}_{2}$ concentrations across the urban sites are marginally lower using MEIC Opt compared to MEIC Std, with the reverse true at suburban site 11 , again reflecting the relocation of emissions out of the urban centre.

The much closer agreement between measured $\mathrm{NO}_{x}$ concentrations at the IAP field site and those simulated with MEIC Opt compared to MEIC Std, outlined in Sect. 3.2, is further emphasised by the diurnal cycles in Fig. 11. MEIC Opt produces much lower $\mathrm{NO}_{x}$ concentrations than MEIC Std across all hours of the day (up to a factor of 3), peaking during morning and evening rush hour with concentrations of $\sim 200$ and $\sim 250 \mu \mathrm{g} \mathrm{m}^{-3}$, respectively. The simulated $\mathrm{NO}_{2} / \mathrm{NO}_{x}$ concentration ratio at IAP produced with MEIC Opt ranges from 0.4 to 0.7 throughout the day, 0.20.3 greater than the MEIC Std simulation. This again reflects the combined influences of both the greater $\mathrm{NO}_{2} / \mathrm{NO}_{x}$ emission ratio in MEIC Opt (Table 2) and the non-linear response of secondary $\mathrm{NO}_{2}$ concentrations to $\mathrm{NO}_{x}$ emission changes, as discussed in Sect. 3.2. Overestimated $\mathrm{NO}_{x}$ concentrations and underestimated $\mathrm{NO}_{2} / \mathrm{NO}_{x}$ concentrations ratios at IAP produced with MEIC Opt indicate that, despite emissions modifications, the magnitudes of $\mathrm{NO}_{x}$ emissions (specifically NO) are too high in the MEIC Opt inventory. 


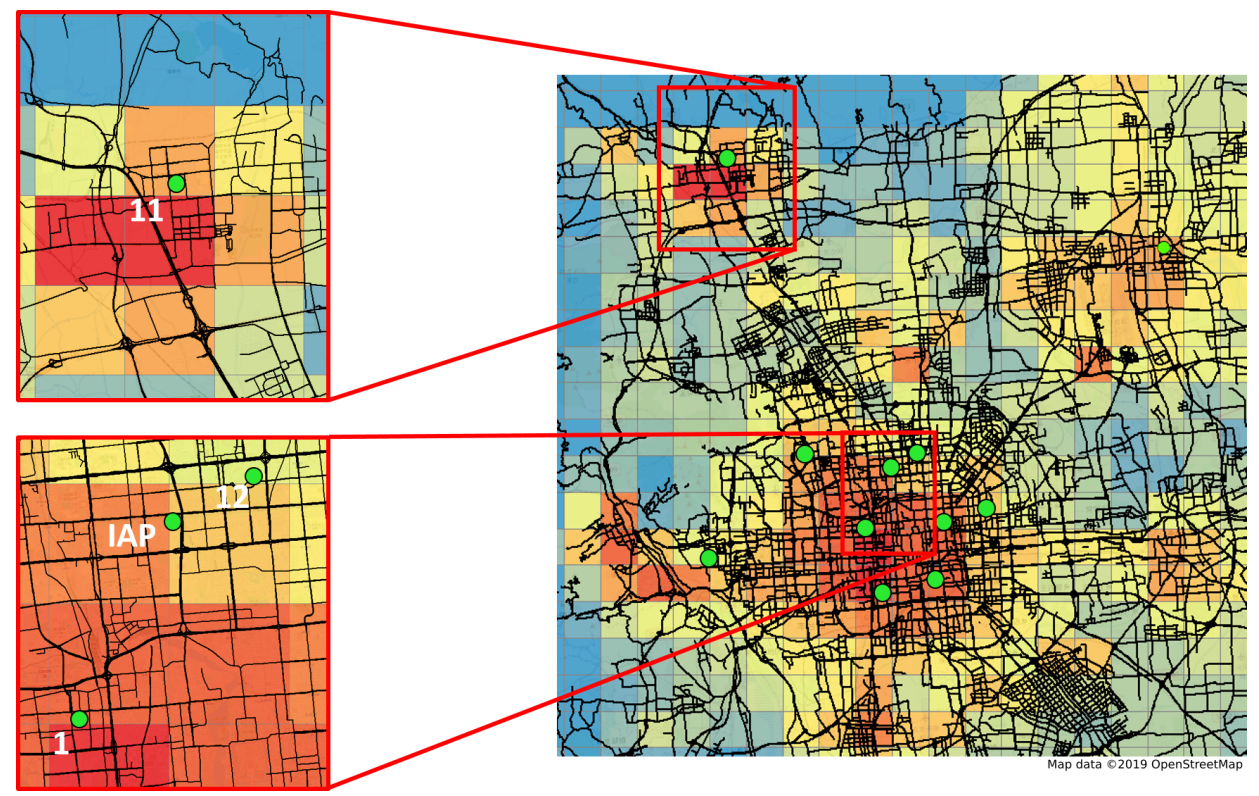

Figure 9. Spatial distribution of November and December mean MEIC Opt $\mathrm{NO}_{2}$ emissions (all emission sectors) overlaid with Beijing road network (source: OpenStreetMap, 2019). Enlarged regions cover urban sites 1, 12 and IAP as well as suburban site 11. Right panel: (C) OpenStreetMap contributors 2019. Distributed under a Creative Commons BY-SA License.
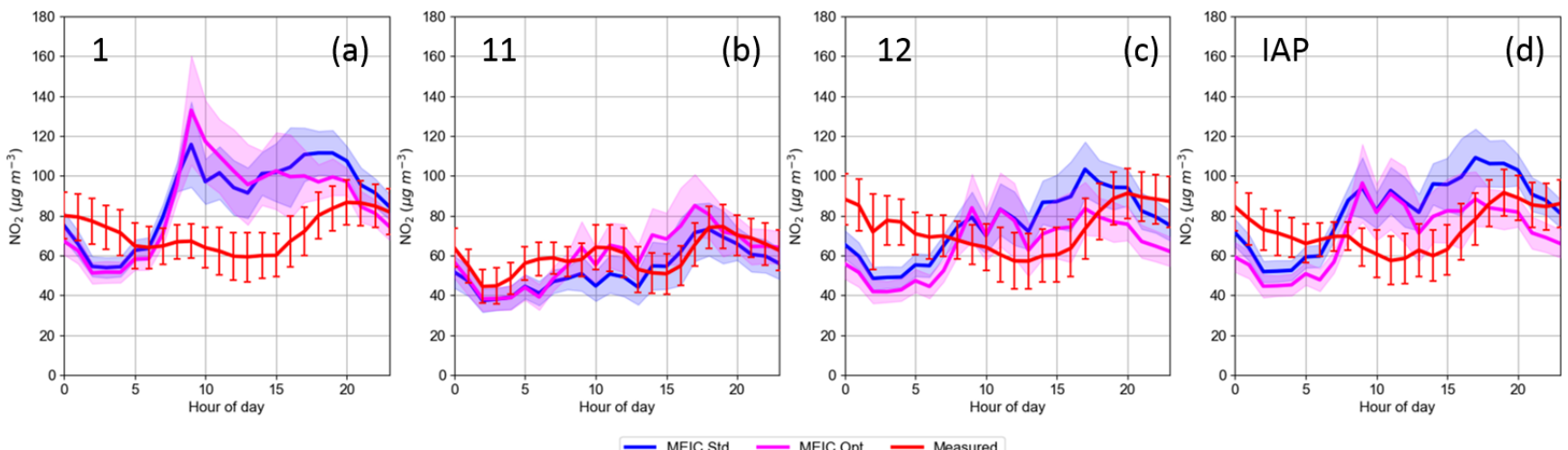

Figure 10. Campaign period mean diurnal variation in modelled and measured $\mathrm{NO}_{2}$ concentrations at sites (a) 1 , (b) 11 , (c) 12 , and (d) IAP. Modelled concentrations produced using both MEIC Std (blue) and MEIC Opt (pink). Measurements marked by red line. Shaded areas and error bars represent the $95 \%$ confidence intervals for simulated and measured concentrations, respectively.

The impact of $\mathrm{NO}_{x}$ emission differences on diurnal $\mathrm{O}_{3}$ concentrations is illustrated in Fig. 12. Using MEIC Std, simulated $\mathrm{O}_{3}$ concentrations across all three urban sites are considerably lower than measured values from 08:00 to $17: 00$, with the measured-modelled difference reaching $\sim 20 \mu \mathrm{g} \mathrm{m}^{-3}$ at midday. This reflects the prominence of Reaction (R4), caused by high urban NO emissions in MEIC Std. The reverse response is seen at site 11 , where midday $\mathrm{O}_{3}$ is overestimated by $\sim 10 \mu \mathrm{g} \mathrm{m}^{-3}$ as a result of low MEIC Std NO emissions in suburban versus urban regions. During daylight hours, there is much closer agreement between measured and modelled $\mathrm{O}_{3}$ across all four sites with MEIC Opt. This reflects the adjusted balance between photochemi- cal production of $\mathrm{O}_{3}$, via Reaction (R3), and its removal via Reaction (R4), caused by decreased $\mathrm{NO}_{x}$ emissions in urban areas and increased emissions in suburban areas, in the MEIC Opt inventory. $\mathrm{NO}_{x}-\mathrm{O}_{3}$ chemistry is also greatly influenced by proximity to road sources. As shown in Fig. 8 and discussed in Sect. 3.2, roads with higher $\mathrm{NO}_{x}$ emissions lead to lower $\mathrm{NO}_{2} / \mathrm{NO}_{x}$ concentration ratios within distances of $100 \mathrm{~m}$ and therefore greater $\mathrm{O}_{3}$ loss through its titration by NO in Reaction (R4). 

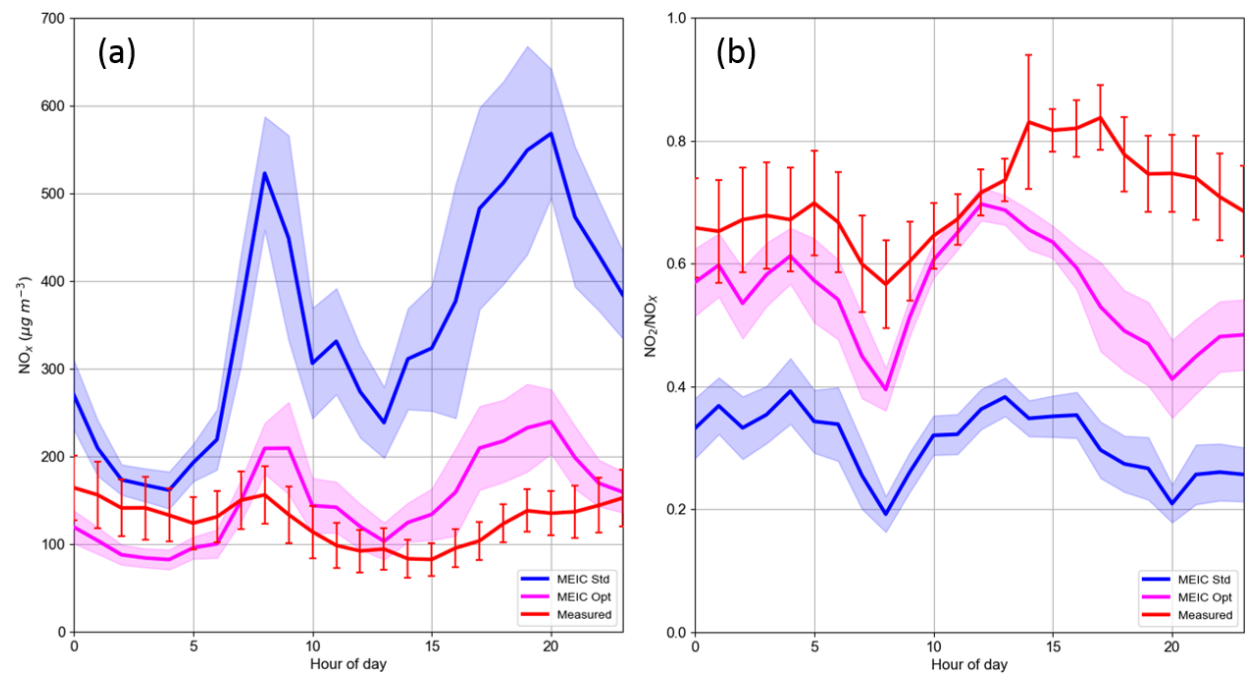

Figure 11. Campaign period mean diurnal variation in modelled and measured (a) $\mathrm{NO}_{x}$ concentrations and (b) $\mathrm{NO}_{2} / \mathrm{NO}_{x}$ concentration ratios at the IAP field site. Modelled concentrations produced using both MEIC Std (blue) and MEIC Opt (pink). Measurements marked by red line. Shaded areas and error bars represent the $95 \%$ confidence intervals for simulated and measured concentrations, respectively.
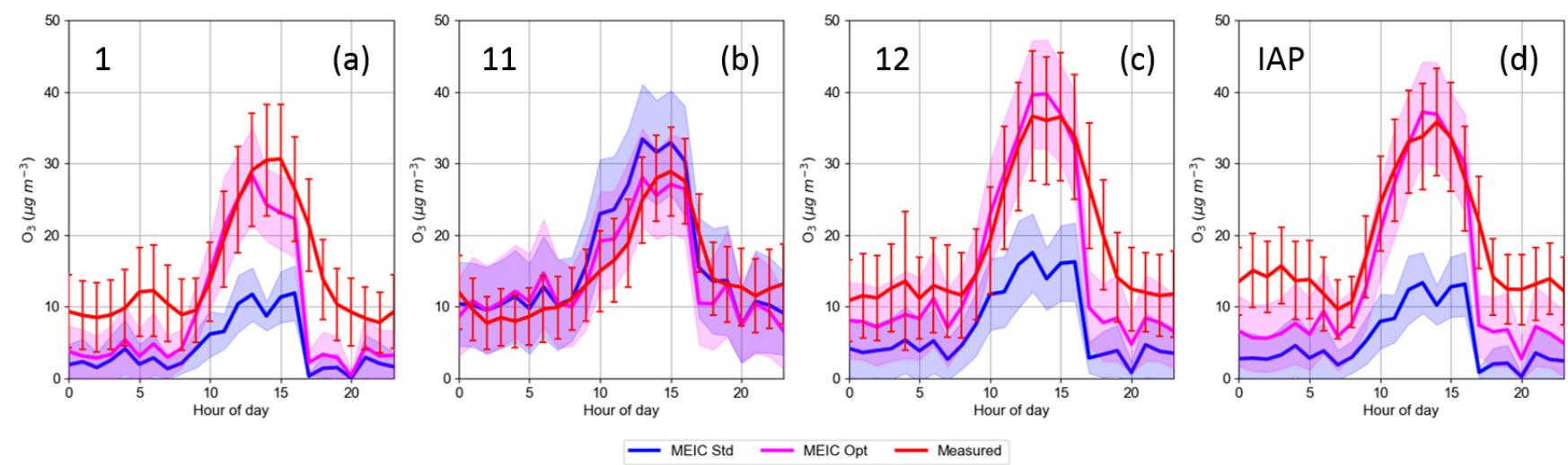

Figure 12. Campaign period mean diurnal variation in modelled and measured $\mathrm{O}_{3}$ concentrations at sites (a) 1 , (b) 11 , (c) 12 and (d) IAP. Modelled concentrations produced using both MEIC Std (blue) and MEIC Opt (pink). Measurements marked by red line. Shaded areas and error bars represent the $95 \%$ confidence intervals for simulated and measured concentrations, respectively.

\subsection{Local and regional contributions to $\mathrm{PM}_{2.5}$ concentrations}

Figure 13 presents the diurnal variation of the range of site-specific campaign period mean measured and simulated $\mathrm{PM}_{2.5}$ concentrations, using MEIC Opt, across all 12 monitoring network sites. The interquartile range of all network measurements, illustrating the extent to which $\mathrm{PM}_{2.5}$ concentrations vary spatially across the domain, greatly exceeds that of modelled concentrations for most of the day. This observed range is largest at night and consistently in excess of $20 \mu \mathrm{g} \mathrm{m}^{-3}$, compared to the simulated range of $5-10 \mu \mathrm{g} \mathrm{m}^{-3}$. The measured ranges are additionally sub-divided into those recorded at urban and suburban monitoring sites, with the diurnal median urban $\mathrm{PM}_{2.5}$ values as much as $\sim 35 \mu \mathrm{g} \mathrm{m}^{-3}$ higher than those for suburban sites between 23:00 and
02:00. It is possible that, similarly to the elevated evening $\mathrm{NO}_{2}$ concentration measurements discussed in Sect. 3.3, this high measured nighttime urban $\mathrm{PM}_{2.5}$ concentration increment is also related to the influx of HDDTs to central Beijing following the lifting of traffic restrictions from 23:00 to 06:00, with recent studies (Y. Zhang et al., 2015; Wu et al., 2016) reporting a rising contribution from HDDT exhaust emissions to $\mathrm{PM}_{2.5}$ levels across China. A subsequent reduction of the measured urban-suburban $\mathrm{PM}_{2.5}$-level discrepancy during daytime hours, reaching $\sim 10 \mu \mathrm{g} \mathrm{m}^{-3}$ at midday, coincides with much closer overall agreement between modelled and measured concentrations.

The large difference between mean measured urban and suburban $\mathrm{PM}_{2.5}$ concentrations throughout the day in Fig. 13 is not captured by the model. This is likely the result of either a lack of heterogeneity in the modelled $\mathrm{PM}_{2.5}$ emis- 


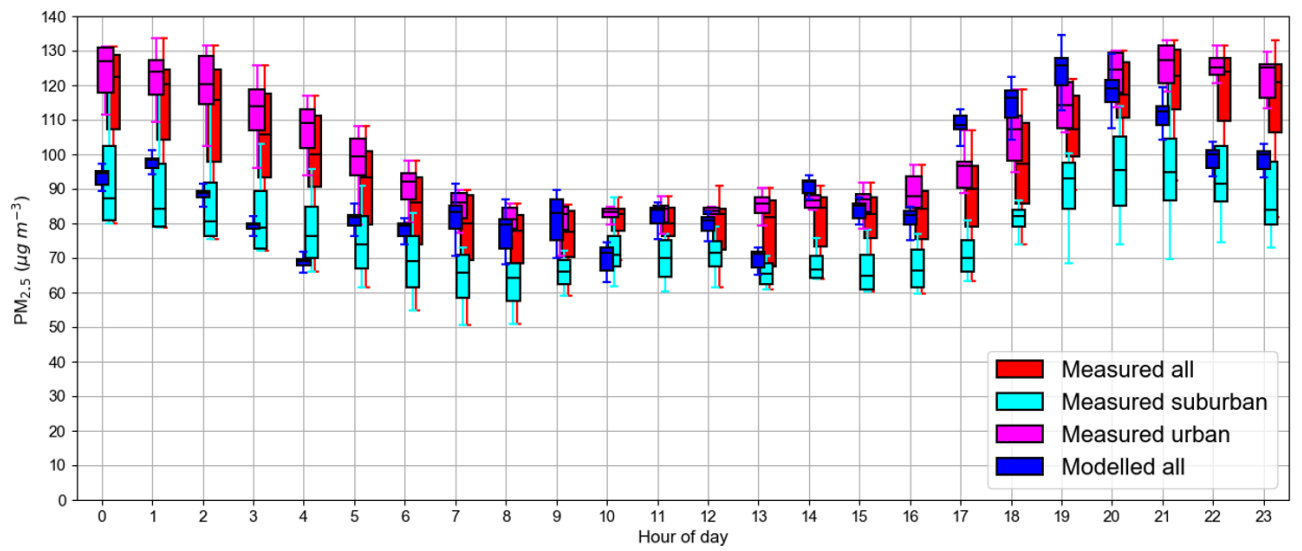

Figure 13. Variations in site-specific campaign period mean measured (red) and modelled (blue) $\mathrm{PM}_{2.5}$ concentrations across all monitoring network stations for each hour of the day. Measurements sub-divided to highlight the variation between suburban (cyan) and urban (pink) monitoring network stations specifically.

sion sources, particularly across urban areas, or that, in reality, substantial non-uniformity in the background concentration exists across the domain. The former is consistent with a number of previous studies on $\mathrm{PM}_{2.5}$ source apportionment in Beijing, which have suggested that, during extended periods of elevated particulate mass concentrations in winter, local emissions can account for $80 \%$ of $\mathrm{PM}_{2.5}$ concentrations (Li et al., 2017; Y. Wang et al., 2017; Chang et al., 2019). Therefore, as discussed in Sect. 3.2, in order to simulate the high spatial variation of $\mathrm{PM}_{2.5}$ concentrations, characterised by large urban $\mathrm{PM}_{2.5}$ concentration increments, higher-resolution modelling of primary $\mathrm{PM}_{2.5}$ emissions through the inclusion of explicitly represented large point sources is likely to be necessary.

It is also possible that greater secondary aerosol production needs to be included in the model's chemistry scheme, further increasing the simulated urban $\mathrm{PM}_{2.5}$ increment. Currently in ADMS-Urban, with the exception of ammonium sulfate production, secondary $\mathrm{PM}_{2.5}$ concentrations are assumed to be included in the upwind background concentration. As the dominant contribution to secondary $\mathrm{PM}_{2.5}$ in Beijing is reported to be from neighbouring industrial regions to the south (Ma et al., 2017), this assumption seems largely valid. However, the relative local contributions of other secondary components in Beijing, such as ammonium nitrates, are found to be increasing (Y. Wang et al., 2017; Xu et al., 2019; Yang et al., 2019). This is a consequence of the effectiveness of recent $\mathrm{SO}_{2}$ emission controls and the lack of agricultural ammonia $\left(\mathrm{NH}_{3}\right)$ emissions reductions (Zheng et al., 2018), which have promoted the formation of ammonium nitrate (Xu et al., 2019). Xu et al. (2019) also found the nitrate aerosol to be of increasing importance at night during winter, as a result of its greater stability at lower temperatures, which, coupled with high nighttime $\mathrm{NO}_{2}$ concentrations (Fig. 10), may further account for the elevated evening $\mathrm{PM}_{2.5}$ levels (Fig. 13). The applicability of this pre- vious work is possibly limited by the smaller domain size and short timescales of pollution dispersion in this study compared with those necessary for secondary aerosol production. However, future work testing the impact of both the higher-resolution representation of $\mathrm{PM}_{2.5}$ emission sources and additional secondary particle formation pathways within the chemistry scheme is needed to fully understand the potential impact of both on improving agreement between simulated and measured $\mathrm{PM}_{2.5}$ concentrations (Fig. 13).

The regional contribution to total $\mathrm{PM}_{2.5}$ concentrations in Beijing has been shown by previous studies to vary from $<10 \%$ to $>90 \%$ depending on the time of year and meteorological conditions (He et al., 2015; Liu et al., 2015; Li et al., 2017; Y. Wang et al., 2017). Therefore, the sensitivity of the calculated $\mathrm{PM}_{2.5}$ background concentration to the methodology used to select the appropriate monitoring site is important and is illustrated in Fig. 14. As described in Sect. 2.1.4, simulated $\mathrm{PM}_{2.5}$ concentrations include a wind directiondependent upwind background contribution calculated using either of two sites to the north or one to the south of urban Beijing. Figure 14 shows the diurnal range of calculated upwind background values during the winter campaign, with the corresponding range of background $\mathrm{PM}_{2.5}$ calculated by instead selecting the minimum hourly concentration across the monitoring network, matching the methodology used to determine background concentrations for gaseous species.

For each hour, the upwind background $\mathrm{PM}_{2.5}$ upper quartile, median and lower quartile greatly exceed the corresponding values when using the minimum background methodology. This discrepancy is greatest for the upper quartile values and peaks during morning and evening rush hour, reaching $\sim 80 \mu \mathrm{g} \mathrm{m}^{-3}$ at 17:00 (Fig. 14). The lower whiskers, however, denoting the lowest datum lying within 1.5 times the interquartile range of the lower quartile, are common across both sets of $\mathrm{PM}_{2.5}$ background diurnal cycles. Interpretation of these results is assisted by Fig. 15, which 


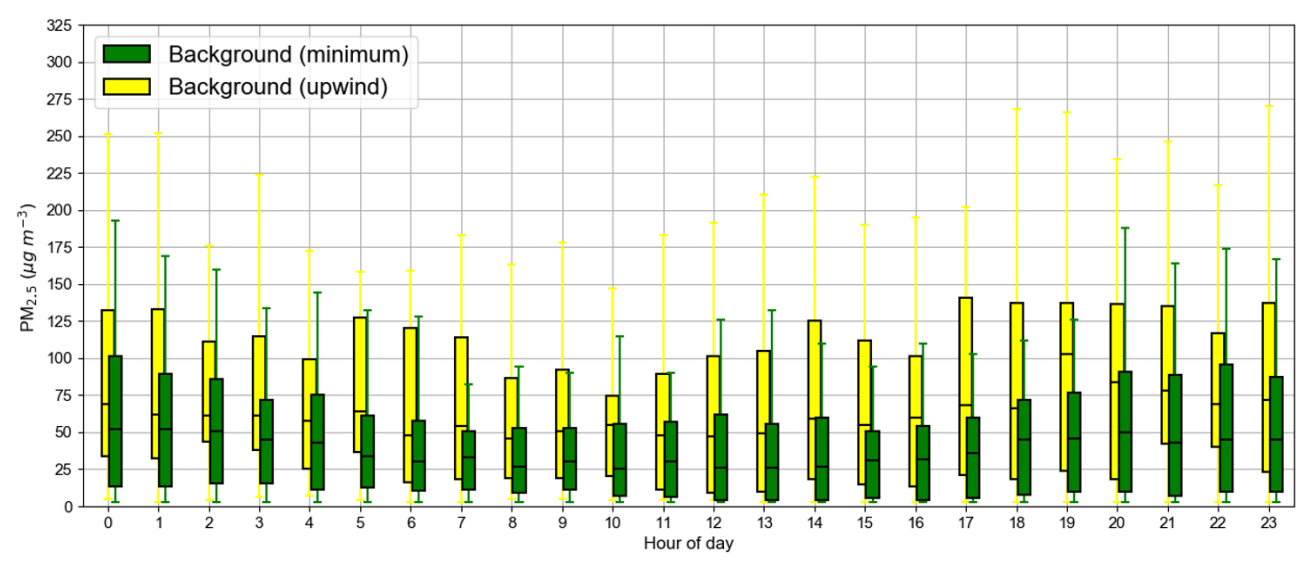

Figure 14. Ranges in campaign period mean calculated background $\mathrm{PM}_{2.5}$ concentrations for each hour of the day using minimum (green) and upwind (yellow) concentration methodologies.

presents hourly wind vectors and $\mathrm{PM}_{2.5}$ time series measurements throughout the campaign at all three upwind sites as well as urban sites 1 and 2. It is clear that the highest upwind $\mathrm{PM}_{2.5}$ background concentrations occur when values at the additional site to the southeast of urban Beijing (site 14) are selected during periods of southerly winds (Fig. 15). The lowest background concentrations, therefore, can be attributed to either of the northerly sites (site 3 and site 10). Northerly winds advect clean air originating over the relatively unpolluted mountainous regions into urban Beijing (Tie et al., 2015). This switch in wind directions creates a saw-tooth pattern, with pollution episodes initially consisting of a slow build-up phase, associated with stagnant southerly winds, and culminating with sharp concentration drops related to the influx of cold northerly air ( $\mathrm{Li}$ et al., 2017; Y. Wang et al., 2017). A clear example of this, from 23 to 27 November, is shown in Fig. 15.

$\mathrm{PM}_{2.5}$ concentrations at site 14 , situated in the southeastern corner of the model domain, are consistently higher than those measured at sites located in central Beijing. This monitoring station is located in the built-up Guangyang District of Langfang in Hebei province and is not in the immediate vicinity of any large point sources. Therefore, this region is possibly more heavily influenced by regional $\mathrm{PM}_{2.5}$ advected from industrial towns and cities to the south. This highlights an important limitation of our study, which assumes a homogeneous background concentration for each species; this assumption may not be valid across such a large and complex urban area.

Both local $\mathrm{PM}_{2.5}$ emission sources not represented in our study and background inhomogeneity appear to contribute substantially to differences in the spatial and temporal variation of measured and modelled $\mathrm{PM}_{2.5}$ concentrations. However, the large diurnal variability in measured $\mathrm{PM}_{2.5}$ concentration ranges across the domain (Fig. 13), not captured by the model, is more likely the influence of local emis- sion sources, with longer timescales required for background $\mathrm{PM}_{2.5}$ concentration variability driven by regional transport.

\subsection{Impact of explicit road source modelling}

In this section, we investigate the sensitivity of the simulated $\mathrm{NO}_{2}$ concentrations to the inclusion of explicit road source emissions. Simulations that use aggregate 3-D grid sources alone are much less computationally expensive than those that also incorporate explicit road source emissions and allow studies to be performed with ADMS-Urban in urban areas where detailed road network information is unavailable. In Fig. 16, measured $\mathrm{NO}_{2}$ concentrations averaged across the campaign are compared with those simulated using 3D grid and explicit road sources, as well as 3-D grid sources only, derived from the MEIC Opt emissions inventory. By resolving road traffic emissions into explicitly represented road sources, as opposed to using gridded emissions only, mean modelled $\mathrm{NO}_{2}$ concentrations across urban stations increase from 62.8 to $71.4 \mu \mathrm{g} \mathrm{m}^{-3}$ (Table 5). This modelled urban $\mathrm{NO}_{2}$ concentration increase results in a $\mathrm{Fb}$ value improvement from -0.13 to 0 (Table 5) reflecting the greater $\mathrm{NO}_{2}$ levels simulated by the model at locations in close proximity to explicit roads. By using grid sources only, the road traffic emissions are diluted over each $3 \times 3 \mathrm{~km}$ grid cell and the strong concentration gradients associated with a region densely populated by major roads, illustrated in Fig. 4, are not captured. Similarly, Dédelé and Miskinyté (2015) and Hood et al. (2018) found that increased traffic emissions due to higher traffic volume and adjusted emission factors, respectively, produced improved $\mathrm{Fb}$ values using ADMSUrban.

More accurate model predictions next to roads can lead to better assessments of human exposure levels to pollutant species and are evidence of the successful implementation of the top-down approach to estimating explicit road traffic emissions used in this study. However, it is also clear from 


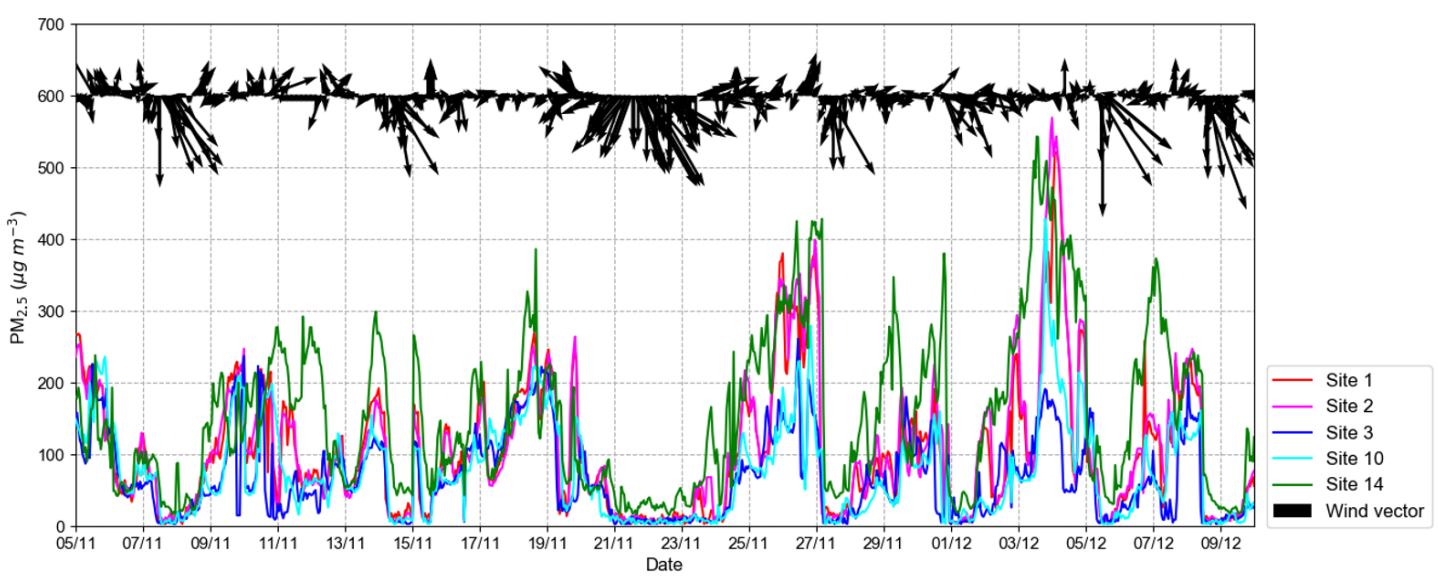

Figure 15. Hourly $\mathrm{PM}_{2.5}$ concentrations at measurement sites $1,2,3,10$ and 14 during the campaign period. Wind vectors, representing wind speed magnitude and direction recorded at the airport meteorological station, are also provided (black arrows).

Table 5. Same information presented as in Table 4 but for $\mathrm{NO}_{2}$ concentrations simulated (MEIC Opt) using 3-D grid sources only (G) as well as 3-D grid and explicit road sources (G-R) (also presented in Table 4).

\begin{tabular}{|c|c|c|c|c|c|c|c|c|c|c|}
\hline & \multirow{2}{*}{\multicolumn{4}{|c|}{ Mean concentrations $\left(\mu \mathrm{g} \mathrm{m}^{-3}\right)$}} & \multicolumn{6}{|c|}{ Model evaluation statistics } \\
\hline & & & & & \multicolumn{2}{|c|}{ NMSE } & \multicolumn{2}{|c|}{$\mathrm{Fb}$} & \multicolumn{2}{|c|}{$R$} \\
\hline & Site & $\operatorname{Mod}(\mathrm{G})$ & $\operatorname{Mod}(\mathrm{G}-\mathrm{R})$ & Obs & G & G-R & G & G-R & $\mathrm{G}$ & G-R \\
\hline \multirow[t]{3}{*}{$\mathrm{NO}_{2}$} & All & 58.9 & 65.7 & 65.3 & 0.28 & 0.30 & -0.10 & 0.00 & 0.59 & 0.53 \\
\hline & Urb & 62.8 & 71.4 & 71.3 & 0.29 & 0.31 & -0.13 & 0.00 & 0.51 & 0.44 \\
\hline & Sub & 50.1 & 52.9 & 51.8 & 0.21 & 0.23 & -0.03 & 0.02 & 0.73 & 0.70 \\
\hline
\end{tabular}

Fig. 16 that agreement between modelled and measured $\mathrm{NO}_{2}$ concentrations at sites 1 and 2 is substantially poorer when using explicit road sources than with the grid-source-only simulation. The model evaluation statistics for all monitoring sites (Table 5) reflect this with increases in NMSE from 0.28 to 0.3 and decreases in $R$ from 0.59 to 0.53 when modelling road emissions explicitly. As discussed in Sect. 3.2, this highlights the impact that the assumption of constant traffic activity, high underlying gridded emissions or the absence of street canyon and urban canopy modelling can have on simulated concentrations at certain near-road locations.

Minimal $R$ value changes and a much lower $\mathrm{Fb}$ improvement, -0.03 to 0.02 , are seen across suburban compared to urban areas, following the inclusion of explicit road source emissions. This reflects the lower density of roads in suburban areas (Fig. 4) and therefore the absence of strong concentration gradients that enhance $\mathrm{NO}_{2}$ levels at near-road urban locations. The relative influence of diffuse emissions contained within the underlying gridded emission sources on simulated pollutant concentrations is therefore more prominent with distance from Beijing's urban centre, with previous studies specifically highlighting the persisting importance of residential coal combustion for heating and cooking during winter in suburban and rural Beijing (Cai et al., 2018; Li et al., 2018).

\subsection{Accounting for additional evening $\mathrm{NO}_{x}$ emission source}

In this section, the influence of modifying the MEIC diurnal emissions profile, used for all previous simulations, to account for additional sources of nighttime $\mathrm{NO}_{x}$ emissions is examined. As discussed in Sect. 3.3, a likely explanation for the simulated underestimate in nocturnal $\mathrm{NO}_{x}$ and $\mathrm{NO}_{2}$ concentrations is that an additional evening $\mathrm{NO}_{x}$ emission source is not accounted for in the emissions inventories. The timing of these peak $\mathrm{NO}_{2}$ and $\mathrm{NO}_{x}$ measurements, between 23:00 and 06:00, coincides with the influx of HDDTs within Beijing's Fourth Ring Road.

Figure 17 presents the standard MEIC diurnal emissions profile (DP_MEIC), and two alternative profiles, DP 25 and DP_50, constructed by increasing the standard MEIC profile factors between 23:00 and 06:00 by $\sim 0.25$ and $\sim 0.5$, respectively, to account for additional nighttime HDDT emissions. For both modified emissions profiles, in order to retain the same $24 \mathrm{~h}$ emissions total, DP_MEIC is further adjusted between 07:00 and 22:00, by magnitudes that also preserve the timings of the morning and evening emissions peaks associated with rush hour traffic. The weekend emissions profile, characterised by a delayed morning peak and $\sim 30 \%$ 


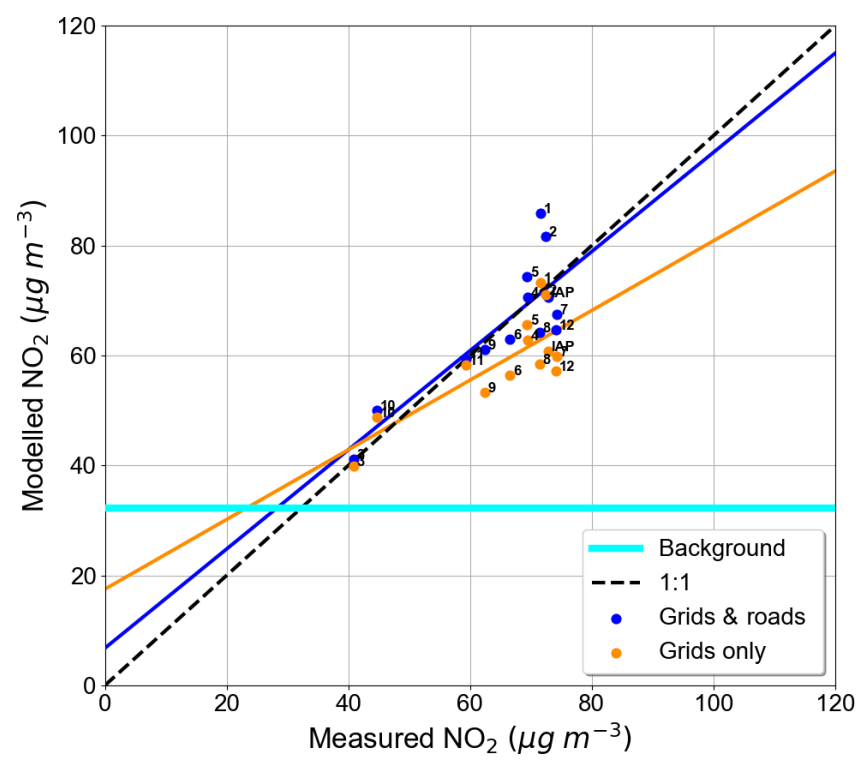

Figure 16. Campaign period measured and modelled $\mathrm{NO}_{2}$ concentrations at all the measurement sites (numbered). Modelled concentrations produced using 3-D grid and explicit road emission sources (blue) and 3-D grid sources only (orange) derived from the MEIC Opt emissions inventory. Horizontal light blue line represents campaign period mean background $\mathrm{NO}_{2}$ concentrations calculated from measurements.

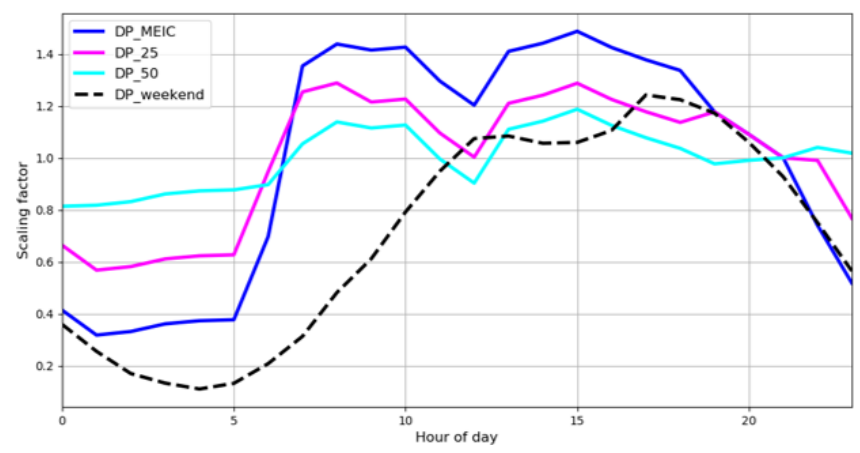

Figure 17. Diurnal emissions profiles applied to the simulations shown in Fig. 18. Standard MEIC diurnal emissions profile (DP_MEIC) marked by blue line; modified DP_MEIC with increased proportions of nighttime emissions marked by pink (DP_25) and cyan (DP_50) lines and weekend emissions profile marked by dashed black line.

reduced total daily traffic emissions, is kept unchanged for all three sensitivity simulations.

Campaign period mean diurnal profiles of $\mathrm{NO}_{2}$ concentrations, simulated using the diurnal emissions profiles shown in Fig. 17, are presented in Fig. 18. At suburban site 11, the close agreement between simulated and measured $\mathrm{NO}_{2}$ concentrations using DP_MEIC is strengthened further by increasing the proportion of emissions released at night relative to the daytime. Modelled $\mathrm{NO}_{2}$-level overestimations throughout the morning and afternoon hours at sites 12 and
IAP using DP_MEIC are reduced when applying the two modified emissions profiles. However, at site 1 the application of DP_50 is unable to reduce daytime $\mathrm{NO}_{2}$ concentrations substantially, which is likely related again to the effect of overestimated emissions along the nearest explicit road source (Fig. 8). The evening $\mathrm{NO}_{2}$ concentration is underestimated at sites 1, 12 and IAP, using DP_MEIC, and this is successively reduced by a small amount with DP_25 and DP_50. The remaining evening differences suggest that, although the inclusion of higher nighttime emissions improves agreement, other possible issues exist related to ADMS-Urban's inability to model dispersion at very low wind speeds; inaccurate underlying gridded emissions; the simplified GRS chemistry scheme; and the exclusion of street canyon and urban canopy modelling or PBL dynamics.

\subsection{The influence of boundary layer height and stability on diurnal $\mathrm{NO}_{2}$ concentrations}

In this section, the impact of PBLH and stability on diurnal $\mathrm{NO}_{2}$ concentrations is explored with further sensitivity simulations. The space into which emitted plumes of pollutants can disperse and mix is determined by the PBLH. Figure 19 shows the difference between measured and modelled PBLHs and their impact on simulated diurnal $\mathrm{NO}_{2}$ concentrations. Differences between the PBLH simulated without evening stability adjustment and the observed PBLH (Fig. 19) are characterised by a daytime overprediction and nighttime underprediction. At 15:00, the rapidly growing convective PBL peaks at $\sim 1100 \mathrm{~m}$, exceeding the observed heights by $\sim 200 \mathrm{~m}$. This difference between observed and simulated PBLHs could be a result of an overestimation of the solar radiation-driven surface sensible heat flux and mechanically driven turbulent flux values, which are the principal parameters impacting the modelled PBLH. Additionally, due to complex cloud physics, detecting the exact limit of vertical mixing is difficult in the presence of low-level stratiform clouds, which form frequently in Beijing during winter, and may further account for low PBLHs derived from ceilometer observations (Kotthaus and Grimmond, 2018). After sunset at 17:00, the modelled PBLH shrinks to $200 \mathrm{~m}, 400 \mathrm{~m}$ below the measured height. This sharp transition between an unstable and a stable modelled PBL is a consequence of ADMS-Urban not accounting for the UHI effect in its surface energy balance calculations, as described in Sect. 2.1.2.

The early evening stability adjustment (Sect. 2.1.2) applied to all previous simulations in this study replicates the effect of the UHI by reducing PBL stability between 16:00 and 19:00. By applying the stability modification, early evening modelled PBLH increases and reaches $\sim 1300 \mathrm{~m}$ by 18:00 before sharply decreasing to $\sim 200 \mathrm{~m}$ by $20: 00$. Note that directly input PBLH measurements are unaffected by changes to $L_{\mathrm{MO}}$ and surface heat flux terms. The stability adjustment reduces $\mathrm{NO}_{2}$ concentrations simulated at 

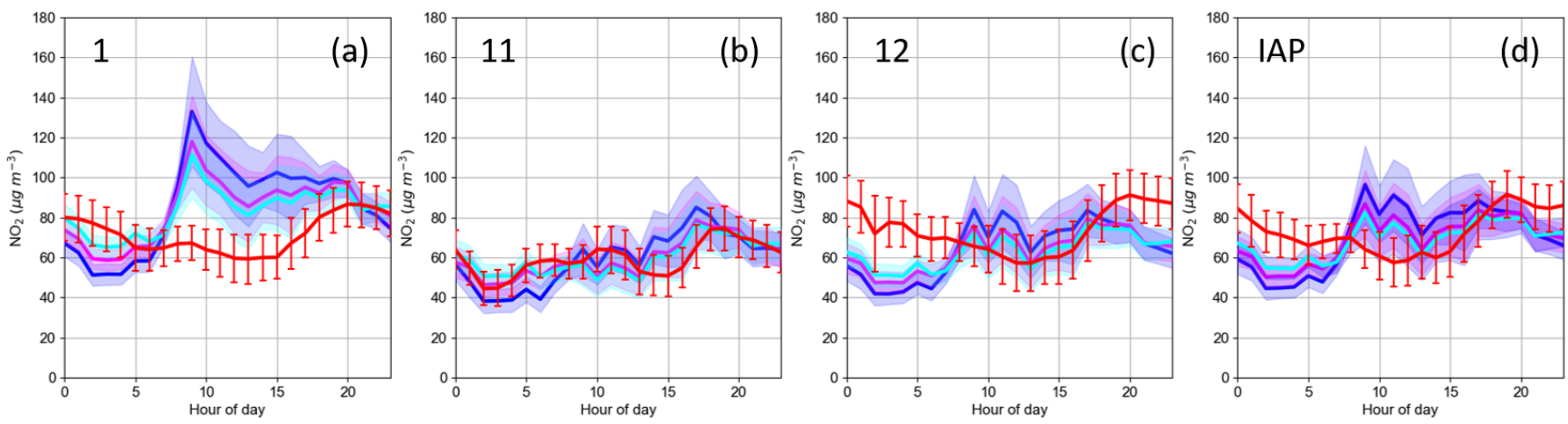

— Modelled $\mathrm{NO}_{2}$ (DP_MEIC) - Modelled $\mathrm{NO}_{2}$ (DP_25) - Modelled $\mathrm{NO}_{2}$ (DP_50) - Measured $\mathrm{NO}_{2}$

Figure 18. Campaign period mean diurnal variation in measured and modelled $\mathrm{NO}_{2}$ concentrations using MEIC Opt at sites (a) 1 , (b) 11 , (c) 12, and (d) IAP. Measurements marked by red line. Shaded areas and error bars represent the $95 \%$ confidence intervals for simulated and measured concentrations, respectively.
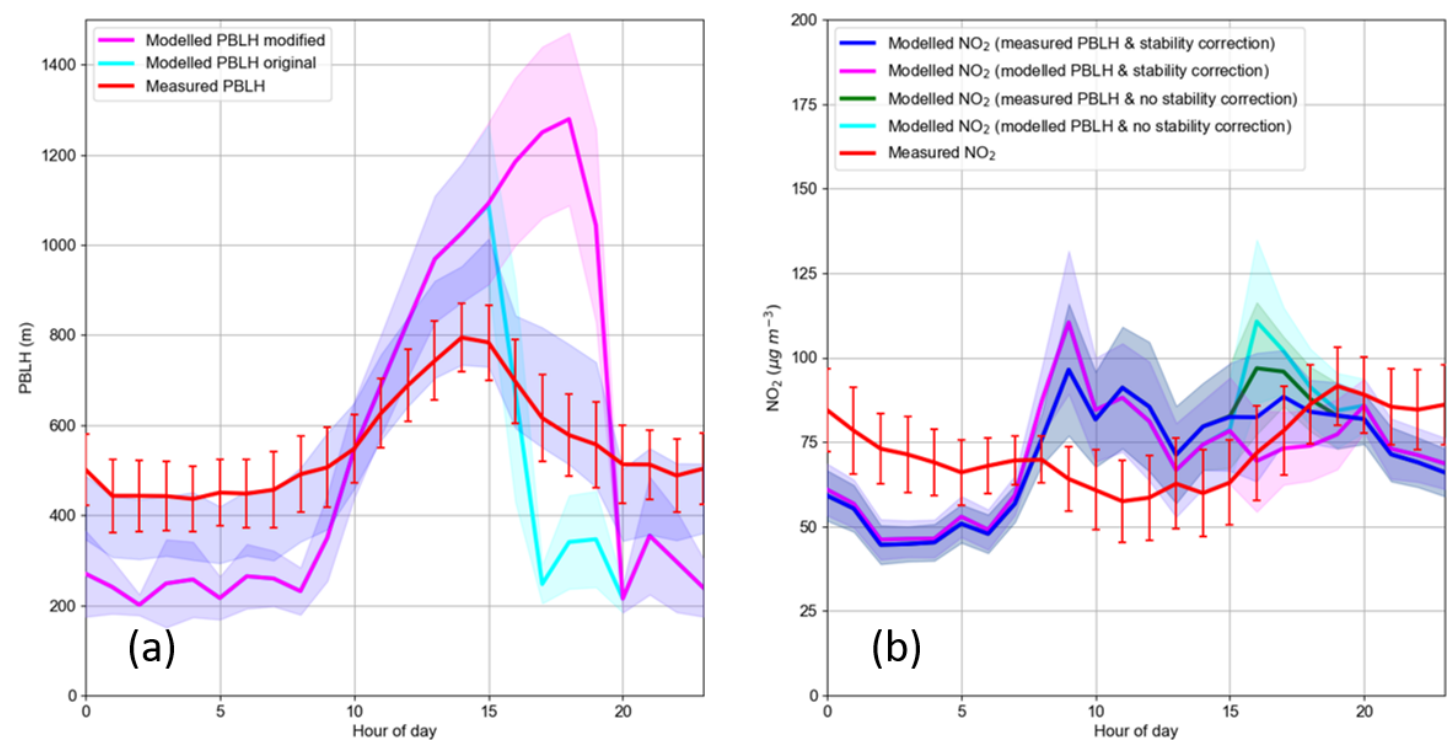

Figure 19. (a) Campaign period mean diurnal variation in modelled PBLH with stability correction (pink), modelled PBLH without stability correction (cyan) and measured PBLH (red). (b) Campaign period mean diurnal variation in measured (red) and modelled $\mathrm{NO}_{2}$ concentrations with measured PBLH and stability correction (blue), modelled PBLH with stability correction (pink), measured PBLH without stability correction (green), and modelled PBLH without stability correction (cyan) at the IAP field site. Shaded areas and error bars represent the $95 \%$ confidence intervals for simulated and measured PBLH and concentrations, respectively.

16:00 using modelled and measured PBLHs by $\sim 40$ and $\sim 15 \mu \mathrm{g} \mathrm{m}^{-3}$, respectively, greatly improving agreement with measurements. The sharp morning modelled $\mathrm{NO}_{2}$ concentration rise, peaking at 09:00, decreases by $\sim 10 \mu \mathrm{g} \mathrm{m}^{-3}$ through use of the measured PBLH alone. However, application of a similar PBL stability adjustment, between 07:00 and 10:00, would likely reduce the early morning PBLH underestimation and further weaken the modelled $\mathrm{NO}_{2}$ concentration rise associated with the input of rush hour-related $\mathrm{NO}_{x}$ emissions into a morning PBL that is currently too stable and too shallow compared to observations.
The results suggest that although atmospheric stability modifications have a strong impact on $\mathrm{NO}_{2}$ concentrations, the use of observed PBLH instead of modelled heights has little effect. This is clearest outside the hours in which the stability correction has been applied, when large $(\sim 300 \mathrm{~m})$ measured and modelled mid-afternoon and nighttime PBLH discrepancies have negligible impact on simulated $\mathrm{NO}_{2}$ concentrations. The greater impact of PBL stability changes alone, however, is clearly evidenced by the $\sim 15 \mu \mathrm{g} \mathrm{m}^{-3}$ difference at 16:00 between simulations using measured PBLHs with and without the stability correction. This dominant influence of PBL stability is possibly related to the impact in 
the model configuration of near-surface traffic emissions and the exclusion of elevated point sources, with pollution dispersion from the latter more likely to be restricted by low PBLHs which would then further affect modelled $\mathrm{NO}_{2} \mathrm{lev}$ els.

\section{Conclusions}

In this study, street-scale-resolution concentrations of $\mathrm{NO}_{x}$, $\mathrm{NO}_{2}, \mathrm{O}_{3}$ and $\mathrm{PM}_{2.5}$ are simulated for Beijing, using the Gaussian pollution dispersion and chemistry model, ADMSUrban. Simulations for the APHH-China winter measurement campaign period (5 November-10 December 2016) are driven by an explicit source road traffic emissions inventory, developed for this work using a pseudo top-down methodology. This approach, which involves apportioning an underlying high-resolution gridded emissions inventory onto Beijing's spatial road network, provided by OpenStreetMap, may be applied to investigate the air quality in other cities where detailed bottom-up traffic emissions inventories are unavailable.

Measurements recorded at 12 of Beijing's air quality monitoring network stations and at the Institute of Atmospheric Physics (IAP) field site are compared with simulated pollutant levels generated by the Multi-resolution Emission Inventory for China v1.3 (MEIC Std), at $3 \mathrm{~km}$ resolution, and an optimised version of the same inventory (MEIC Opt). MEIC Opt, which is based on campaign measurements, has lower emissions across urban Beijing (within the Sixth Ring Road) and higher emissions in surrounding suburban areas, resulting in greatly improved agreement between observed and simulated concentrations for all species. Most notably, driven by $\mathrm{NO}$ emission changes, simulated mean $\mathrm{NO}_{x}$ concentrations at the IAP site are lower by more than a factor of 2 using MEIC Opt compared to the MEIC Std inventory. Consequently, modelled urban $\mathrm{O}_{3}$ concentrations increase by $109 \%$, with suburban $\mathrm{O}_{3}$ concentrations decreasing by $7 \%$ in simulations performed with MEIC Opt.

The inclusion of explicit road sources allows sharp $\mathrm{NO}_{2}$ concentration gradients adjacent to major roads to be resolved, leading to generally closer agreement between network measurements and simulated concentrations. However, limitations of the model configuration can lead to modelled $\mathrm{NO}_{2}$ levels that are substantially higher than measurements at some near-road $(\sim 100 \mathrm{~m})$ sites. These model uncertainties stem from the application of uniform weighting factors to roads of the same classification (thus neglecting traffic activity variations), the assumptions inherent to the underlying gridded inventory, and exclusion of the physical barriers to pollution dispersion created by street canyons. Future work could focus on refining the explicit road emissions network created here by testing the impact of adjusting weighting factors for different pollutants and across urban and suburban areas to better account for the impact of traffic congestion and vehicle type, such as HDDTs, on emissions along different road classifications.

Differences in the diurnal variability of measured and simulated $\mathrm{NO}_{2}$ concentrations during the winter campaign period reveal features related to emissions (e.g. local driving restrictions) and the urban heat island (UHI) that air quality modelling studies over large urban areas should consider. For instance, measured $\mathrm{NO}_{2}$ concentrations at urban monitoring sites situated close to roads can reach nighttime values above $80 \mu \mathrm{g} \mathrm{m}^{-3}$, exceeding both morning and evening rush hour levels. This pattern is not reproduced in the simulated $\mathrm{NO}_{x}$ concentrations and is consistent with the evening influx of heavy duty diesel trucks (HDDTs), banned from traversing within the Fourth Ring Road between 06:00 and 23:00. The increase in HDDT traffic at night across urban Beijing is therefore an important local emission source that needs to be included in MEIC and other proxy-based emission inventories. Additionally, modifying modelled PBL stability parameters to replicate early evening (16:00-19:00) instability driven by the delayed release of heat stored in the urban fabric improves the diurnal variation in simulated $\mathrm{NO}_{2}$ concentrations. A similar modification may improve morning model predictions, although it would be difficult to use the presence of a UHI to justify this.

The range in measured $\mathrm{PM}_{2.5}$ concentrations across the monitoring network for the campaign period $\left(\sim 40 \mu \mathrm{g} \mathrm{m}^{-3}\right)$ is much higher than the corresponding simulated range using both MEIC Std $\left(\sim 20 \mu \mathrm{g} \mathrm{m}^{-3}\right)$ and MEIC Opt $\left(\sim 15 \mu \mathrm{g} \mathrm{m}^{-3}\right)$. The large difference between measured suburban and urban $\mathrm{PM}_{2.5}$ levels is also not captured by the model and may indicate any or all of the following: (a) $\mathrm{PM}_{2.5}$ emissions are too low in magnitude and not represented at sufficiently high resolution, particularly across urban areas, (b) the simplified GRS chemistry scheme needs to be modified to increase contributions from locally produced secondary $\mathrm{PM}_{2.5}$, or (c) the assumption of a homogeneous background concentration across complex megacities, such as Beijing, which are heavily influenced by the advection of regional pollution, is not valid.

Sensitivity studies have shown that using explicit road source emissions, including an additional nighttime emission source, and accounting for UHI effects, through enhanced early evening instability conditions, can produce closer agreement between simulated and measured $\mathrm{NO}_{2}$ concentrations.

Street-level modelling, along with the open data sources and methodologies used here, may be applied for future work elsewhere. Quantifying spatiotemporal pollutant distributions at such fine scales is essential for human health exposure-related studies and for informing choices on the emission controls of specific sectors. 
Data availability. All modelled output data presented here may be accessed by contacting the authors. Measurement data are available via the Centre for Environmental Data Analysis (CEDA) depository at https: //catalogue.ceda.ac.uk/uuid/7ed9d8a288814b8b85433b0d3fec0300 (Centre for Environmental Data Analysis (CEDA), 2020) by contacting our APHH-China partners.

Author contributions. MB set up and ran the model with support from JS. MB processed the model outputs with support from JS. This paper was written by MB with guidance from JS, RMD, OW and DC. All the authors read and improved the manuscript. ZS, JL, FAS, SK and SG provided measurement data. JL, QZ, RW and MH provided and processed the emissions data.

Competing interests. Jenny Stocker works for and David Carruthers is a director of CERC, who develop and license the ADMSUrban model.

Special issue statement. This article is part of the special issue "In-depth study of air pollution sources and processes within Beijing and its surrounding region (APHH-Beijing) (ACP/AMT interjournal SI)". It is not associated with a conference.

Acknowledgements. This work was funded by the UK Natural Environment Research Council (NERC) Industrial studentship scheme with CASE support provided by Cambridge Environmental Research Consultants (CERC). We would also like to acknowledge the APHH-China programme.

Financial support. This research has been supported by the Natural Environment Research Council (grant nos. NE/N007794/1, NE/N006941/1, NE/N006925/1, and NE/N006976/1).

Review statement. This paper was edited by Yongjie Li and reviewed by two anonymous referees.

\section{References}

Anandakumar, K.: A study on the partition of net radiation into heat fluxes on a dry asphalt surface, Atmos. Environ., 33, 3911-3918, https://doi.org/10.1016/S1352-2310(99)00133-8, 1999.

Barlow, J. F., Halios, C. H., Lane, S. E., and Wood, C. R.: Observations of urban boundary layer structure during a strong urban heat island event, Environ. Fluid Mech., 15, 373-398, https://doi.org/10.1007/s10652-014-9335-6, 2015.

Bates, J. T., Pennington, A. F., Zhai, X., Friberg, M. D., Metcalf, F., Darrow, L., Strickland, M., Mulholland, J., and Russell, A.: Application and evaluation of two model fusion approaches to obtain ambient air pollutant concentrations at a fine spatial res- olution (250 m) in Atlanta, Environ. Modell. Softw., 109, 182190, https://doi.org/10.1016/j.envsoft.2018.06.008, 2018.

Cai, H. and Xie, S.: Traffic-related air pollution modelling during the 2008 Beijing Olympic Games: The effects of an odd-even day traffic restriction scheme, Sci. Total Environ., 408, 1935-1948, https://doi.org/10.1016/j.scitotenv.2011.01.025, 2011.

Cai, S., Li, Q., Wang, S., Chen, J., Ding, D., Zhao, B., Yang, D., and Hao, J.: Pollutant emissions from residential combustion and reduction strategies estimated via a village-based emission inventory in Beijing, Environ. Poll., 238, 230-237, https://doi.org/10.1016/j.envpol.2018.03.036, 2018.

Cambridge Environmental Research Consultants (CERC): ADMS-Urban Urban Air Quality Management System Version 4.1 User Guide, available at: http://www.cerc.co.uk/ environmental-software/assets/data/doc_userguides/CERC_ ADMS-Urban4.1.1_User_Guide.pdf (last access: 6 June 2019), 2017.

Carruthers, D. J.: airTEXT air quality forecasting system, Towards eEnvironment, GMES meeting, Prague, Czech Republic, 2009.

Centre for Environmental Data Analysis (CEDA): Atmospheric Pollution \& Human Health in a Developing Megacity (APHH), available at: https://catalogue.ceda.ac. uk/uuid/7ed9d8a288814b8b85433b0d3fec0300, last access: 3 March 2020.

Chang, X., Wang, S., Zhao, B., Xing, J., Liu, X., Wei, L., Song, Y., Wu, W., Cai, S., Zheng, H., Ding, D., and Zheng, M.: Contributions of inter-city and regional transport to $\mathrm{PM}_{2.5}$ concentrations in the Beijing-Tianjin-Hebei region and its implications on regional joint air pollution, Sci. Total Environ., 660, 1191-1200, https://doi.org/10.1016/j.scitotenv.2018.12.474, 2019.

Chen, C.-H., Kan, H.-D., Huang, C., Li, L., Zhang, Y.-H., Chen, R.-J., and Chen, B.-H.: Impact of ambient air pollution on public health under various traffic policies in Shanghai, China, Biomed. Environ. Sci., 22, 210-215, https://doi.org/10.1016/S08953988(09)60047-7, 2009.

Chen, S., Xu, L., Zhang, Y., Chen, B., Wang, X., Zhang, X., Zheng, M., Chen, J., Wang, W., Sun, Y., Fu, P., Wang, Z., and Li, W.: Direct observations of organic aerosols in common wintertime hazes in North China: insights into direct emissions from Chinese residential stoves, Atmos. Chem. Phys., 17, 1259-1270, https://doi.org/10.5194/acp-17-1259-2017, 2017.

Chen, W., Yan, L., and Zhao, H.: Seasonal variations of atmospheric pollution and air quality in Beijing, Atmosphere, 6, 1753-1770, https://doi.org/10.3390/atmos6111753, 2015.

Cheng, J., Su, J., Cui, T., Li, X., Dong, X., Sun, F., Yang, Y., Tong, D., Zheng, Y., Li, Y., Li, J., Zhang, Q., and He, K.: Dominant role of emission reduction in $\mathrm{PM}_{2.5}$ air quality improvement in Beijing during 2013-2017: a model-based decomposition analysis, Atmos. Chem. Phys., 19, 6125-6146, https://doi.org/10.5194/acp-19-6125-2019, 2019.

Cimorelli, A. J., Perry, S. G., Venkatram, A., Weil, J. C., Paine, R. J., Wilson, R. B., Lee, R. F., Peters, W. D., and Brode, R. W.: AERMOD: A dispersion model for industrial source applications. Part I: General model formulation and boundary layer characterisation, J. Appl. Meteorol., 44, 682-693, https://doi.org/10.1175/JAM2227.1, 2005.

Cui, J., Lang, J., Chen, T., Mao, S., Cheng, S., Wang, Z., and Cheng, N.: A framework for investigating the air quality variation characteristics based on the monitoring data: Case study 
for Beijing during 2013-2016, J. Environ. Sci., 81, 225-ß237, https://doi.org/10.1016/j.jes.2019.01.009, 2019.

Dédelé, A. and Miskinyté, A.: The statistical evaluation and comparison of ADMS-Urban model for the prediction of nitrogen dioxide with air quality monitoring network, Environ. Monit. Assess., 187, 578, https://doi.org/10.1007/s10661-015-4810-1, 2015.

GBD 2016 Risk Factors Collaborators: Global, regional, and national comparative risk assessment of 84 behavioural, environmental and occupational, and metabolic risks or clusters of risks, 1990-2016: a systematic analysis for the Global Burden of Disease Study 2016, Lancet, 390, 1345-422, 2017.

Grimmond, C. S. B. and Oke, T. R.: Heat storage in urban areas: local-scale observations and evaluation of a simple model, J. Appl. Meteorol., 38, 922-940, https://doi.org/10.1175/15200450(1999)038<0922:HSIUAL>2.0.CO;2, 1999.

Hamilton, I., Stocker, J., Evans, S., Davies, S., Davies, M., and Carruthers, D.: The impact of the London Olympic parkland on the urban heat island, J. Build. Perform. Simu., 7, 119-132, https://doi.org/10.1080/19401493.2013.791343, 2014.

Han, L., Zhou, W., Pickett, S. T., Li, W., and Qian, Y.: Multicontaminant air pollution in Chinese cities, Bull. World Health Organ., 96, 233-242, https://doi.org/10.2471/BLT.17.195560, 2018.

He, H., Tie, X., Zhang, Q., Liu, X., Gao, Q., Li, X., and Gao, Y.: Analysis of the causes of heavy aerosol pollution in Beijing, China: A case study with the WRF-Chem model, Particuology, 20, 32-40, https://doi.org/10.1016/j.partic.2014.06.004, 2015.

Hong, C., Zhang, Q., He, K., Guan, D., Li, M., Liu, F., and Zheng, B.: Variations of China's emission estimates: response to uncertainties in energy statistics, Atmos. Chem. Phys., 17, 1227-1239, https://doi.org/10.5194/acp-17-1227-2017, 2017.

Hood, C., MacKenzie, I., Stocker, J., Johnson, K., Carruthers, D., Vieno, M., and Doherty, R.: Air quality simulations for London using a coupled regional-to-local modelling system, Atmos. Chem. Phys., 18, 11221-11245, https://doi.org/10.5194/acp-1811221-2018, 2018.

Jing, B., Wu, L., Mao, H., Gong, S., He, J., Zou, C., Song, G., $\mathrm{Li}, \mathrm{X}$., and $\mathrm{Wu}, \mathrm{Z}$.: Development of a vehicle emission inventory with high temporal-spatial resolution based on NRT traffic data and its impact on air pollution in Beijing - Part 1: Development and evaluation of vehicle emission inventory, Atmos. Chem. Phys., 16, 3161-3170, https://doi.org/10.5194/acp16-3161-2016, 2016.

Kotthaus, S. and Grimmond, C. S. B.: Atmospheric boundary-layer characteristics from ceilometer measurements. Part 1: A new method to track mixed layer height and classify clouds, Q. J. Roy. Meteor. Soc., 144, 1525-1538, https://doi.org/10.1002/qj.3299, 2018.

Kurtenbach, R., Kleffmann, J., Niedojadlo, A., and Wiesen, P.: primary $\mathrm{NO}_{2}$ emissions and their impact on air quality in traffic environments in Germany, Environ. Sci. Eur., 24, 21, https://doi.org/10.1186/2190-4715-24-21, 2012.

Li, J., Du, H., Wang, Z., Sun, Y., Yang, W., Li, J., Tang, X., Fu, P.: Rapid formation of a severe regional winter haze episode over a mega-city cluster on the North China Plain, Environ. Poll., 223, 605-615, https://doi.org/10.1016/j.envpol.2017.01.063, 2017.

Li, X., Wu, J., Elser, M., Feng, T., Cao, J., El-Haddad, I., Huang, R., Tie, X., Prévôt, A. S. H., and Li, G.: Contributions of residential coal combustion to the air quality in Beijing-Tianjin-Hebei
(BTH), China: a case study, Atmos. Chem. Phys., 18, 1067510691, https://doi.org/10.5194/acp-18-10675-2018, 2018.

Liang, Z., Yang, Y., Qian, Z., Ruan, Z., Chang, J., Vaughn, M. G., Zhao, Q., and Lin, H.: Ambient PM $_{2.5}$ and birth outcomes: Estimating the association and attributable risk using a birth cohort study in nine Chinese cities, Environ. Int., 126, 329-335, https://doi.org/10.1016/j.envint.2019.02.017, 2019.

Liu, F., Zhang, Q., Tong, D., Zheng, B., Li, M., Huo, H., and He, K. B.: High-resolution inventory of technologies, activities, and emissions of coal-fired power plants in China from 1990 to 2010, Atmos. Chem. Phys., 15, 13299-13317, https://doi.org/10.5194/acp-15-13299-2015, 2015.

Liu, F., Zhang, Q., Van der A, R. J., Zheng, B., Tong, D., Yan, L., Zheng, Y., and He, K.: Recent reduction in $\mathrm{NO}_{x}$ emissions over China: synthesis of satellite observations and emission inventories, Environ. Res. Lett., 11, 11, https://doi.org/10.1088/17489326/11/11/114002, 2016.

Liu, F., Beirle, S., Zhang, Q., van der A, R. J., Zheng, B., Tong, D., and He, K.: $\mathrm{NO}_{x}$ emission trends over Chinese cities estimated from OMI observations during 2005 to 2015, Atmos. Chem. Phys., 17, 9261-9275, https://doi.org/10.5194/acp-179261-2017, 2017.

Liu, L., Huang, X., Ding, A., and Fu, C.: Dust-induced radiative feedbacks in north China: A dust storm episode modelling study using WRF-Chem, Atmos. Environ., 129, 43-54, https://doi.org/10.1016/j.atmosenv.2016.01.019, 2016.

Liu, W., Ji, C., Zhong, J., Jiang, X., and Zheng, Z.: Temporal characteristics of the Beijing urban heat island, Theor. Appl. Climatol., 87, 213-221, https://doi.org/10.1007/s00704-005-0192-6, 2007.

Lugon, L., Sartelet, K., Kim, Y., Vigneron, J., and Chrétien, O.: Street-in-Grid modeling of gas-phase pollutants in Paris city, Atmos. Chem. Phys. Discuss., https://doi.org/10.5194/acp-20191087, in review, 2019.

Ma, J., Chu, B., Liu, J., Liu, Y., Zhang, H., and He, H.: $\mathrm{NO}_{x}$ promotion of $\mathrm{SO}_{2}$ conversion to sulfate: An important mechanism for the occurrence of heavy haze during winter in Beijing, Environ. Pollut., 223, 662-669, https://doi.org/10.1016/j.envpol.2017.10.103, 2018.

Ma, Q., Wu, Y., Zhang, D., Wang, X., Xia, W., Xia, Y., Liu, X., Tian, P., Han, Z., Xia, X., Wang, Y., and Zhang, R.: Roles of regional transport and heterogeneous reactions in the $\mathrm{PM}_{2.5}$ increase during winter haze episodes in Beijing, Sci. Total Environ., 599600, 246-253, https://doi.org/10.1016/j.scitotenv.2017.04.193, 2017.

Malkin, T. L., Heard, D. E., Hood, C., Stocker, J., Carruthers, D., MacKenzie, I. A., Doherty, R. M., Vieno, M., Lee, J., Kleffmann, J., Laufs, S., and Whalley, L. K.: Assessing chemistry schemes and constraints in air quality models used to predict ozone in London against the detailed Master Chemical Mechanism, Faraday. Discuss., 189, 589-616, https://doi.org/10.1039/c5fd00218d, 2016.

McHugh, C. A., Sheng, X., and Carruthers, D. J.: Using ADMS models for air quality assessment and management in China, Chinese Journal of Population Resources and Environment, 3, 3-10, https://doi.org/10.1080/10042857.2005.10677419, 2005.

Mohan, M., Bhati, S., Sreenivas, A., and Marrapu, P.: Performance evaluation of AERMOD and ADMS-Urban for total suspended particulate matter concentrations in 
megacity Delhi, Aerosol Air Qual. Res., 11, 883-894, https://doi.org/10.4209/aaqr.2011.05.0065, 2011.

National Bureau of Statistics: China Statistical Yearbook for Regional Economy 2014, China Statistics Press, Beijing, China, 2014.

Ni, Z., Luo, K., Gao, Y., Gao, X., Fan, J., and Cen, K.: Potential air quality improvements from ultralow emissions at coal-fired power plants in China, Aerosol Air Qual. Res., 18, 1944-1951, https://doi.org/10.4209/aaqr.2018.02.0070, 2018.

Oak Ridge National Laboratory (ORNL): LandScan Global Population Database, Oak Ridge National Laboratory, Oak Ridge, TN, USA, 2013.

Oke, T. R.: The energetic basis of the urban heat island, Q. J. Roy. Met. Soc., 108, 1-24, 1982.

OpenStreetMap: available at: http://openstreetmap.org, last access: 6 June 2019.

Owen, B., Edmunds, H. A., Carruthers, D. J., and Singles, R. J.: Prediction of total oxides of nitrogen and nitrogen dioxide concentrations in a large urban area using a new generation urban scale dispersion model with integral chemistry model, Atmos. Environ., 34, 397-406, https://doi.org/10.1016/S13522310(99)00332-5, 2000

Patryl, L. and Galeriu, D.: Statistical performances measures - models comparison, French Alternative Energies and Atomic Energy Commission, 2011.

Petaja, T., Jarvi, L., Kerminen, V.-M., Ding, A. J., Sun, J. N., Nie, W., Kujansuu, J., Virkkula, A., Yang, X., Fu, C. B., Zilitinkevich, S., and Kulmala, M.: Enhanced air pollution via aerosol-boundary layer feedback in China, Sci. Rep., 6, 18998, https://doi.org/10.1038/srep18998, 2016.

Qi, J., Zheng, B., Li, M., Yu, F., Chen, C., Liu, F., Zhou, X., Yuan, J., Zhang, Q., and He, K.: A high-resolution air pollutants emission inventory in 2013 for the BeijingTianjin-Hebei region, China, Atmos. Environ., 170, 156-168, https://doi.org/10.1016/j.atmosenv.2017.09.039, 2017.

Sarwar, G. and Luecken, D.: Impact of an updated carbon bond mechanism on predictions from the CMAQ modelling system: Preliminary assessment, J. Appl. Meteorol. Clim., 47, 3-14, https://doi.org/10.1175/2007JAMC1393.1, 2008.

Shi, Z., Vu, T., Kotthaus, S., Harrison, R. M., Grimmond, S., Yue, S., Zhu, T., Lee, J., Han, Y., Demuzere, M., Dunmore, R. E., Ren, L., Liu, D., Wang, Y., Wild, O., Allan, J., Acton, W. J., Barlow, J., Barratt, B., Beddows, D., Bloss, W. J., Calzolai, G., Carruthers, D., Carslaw, D. C., Chan, Q., Chatzidiakou, L., Chen, Y., Crilley, L., Coe, H., Dai, T., Doherty, R., Duan, F., Fu, P., Ge, B., Ge, M., Guan, D., Hamilton, J. F., He, K., Heal, M., Heard, D., Hewitt, C. N., Hollaway, M., Hu, M., Ji, D., Jiang, X., Jones, R., Kalberer, M., Kelly, F. J., Kramer, L., Langford, B., Lin, C., Lewis, A. C., Li, J., Li, W., Liu, H., Liu, J., Loh, M., Lu, K., Lucarelli, F., Mann, G., McFiggans, G., Miller, M. R., Mills, G., Monk, P., Nemitz, E., O'Connor, F., Ouyang, B., Palmer, P. I., Percival, C., Popoola, O., Reeves, C., Rickard, A. R., Shao, L., Shi, G., Spracklen, D., Stevenson, D., Sun, Y., Sun, Z., Tao, S., Tong, S., Wang, Q., Wang, W., Wang, X., Wang, X., Wang, Z., Wei, L., Whalley, L., Wu, X., Wu, Z., Xie, P., Yang, F., Zhang, Q., Zhang, Y., Zhang, Y., and Zheng, M.: Introduction to the special issue "In-depth study of air pollution sources and processes within Beijing and its surrounding region (APHH-Beijing)", At- mos. Chem. Phys., 19, 7519-7546, https://doi.org/10.5194/acp19-7519-2019, 2019.

Stewart, I. D. and Oke, T. R.: Local climate zones for urban temperature studies, Am. Meteorol. Soc., 93, 1879-1900, https://doi.org/10.1175/BAMS-D-11-00019.1, 2012.

Sun, W., Shao, M., Granier, C., Liu, Y., Ye, C. S., and Zheng, J. Y.: Long-term trends of anthropogenic $\mathrm{SO}_{2}, \mathrm{NO}_{x}, \mathrm{CO}$, and NMVOCs emissions in China, Earth's Future, 6, 1112-1133 https://doi.org/10.1029/2018EF000822, 2018.

Tang, G., Zhu, X., Xin, J., Hu, B., Song, T., Sun, Y., Wang, L., Wu, F., Sun, J., Cheng, M., Chao, N., Li, X., and Wang, Y.: Modelling study of boundary-layer ozone over northern China - Part II: Responses to emission reductions during the Beijing Olympics, Atmos. Res., 193, 83-93, https://doi.org/10.1016/j.atmosres.2017.02.014, 2017.

Tao, J., Zhang, L., Cao, J., and Zhang, R.: A review of current knowledge concerning $\mathrm{PM}_{2.5}$ chemical composition, aerosol optical properties and their relationships across China, Atmos. Chem. Phys., 17, 9485-9518, https://doi.org/10.5194/acp-179485-2017, 2017.

Tie, X., Zhang, Q., He, H., Cao, J., Han, S., Gao, Y., Li, X., and Jia, X. C.: A budgest analysis of the formation of haze in Beijing, Atmos. Environ., 100, 25-36, https://doi.org/10.1016/j.atmosenv.2014.10.038, 2015.

Wang, K., Jiang, S., Wang, J., Zhou, C., Wang, X., and Lee, X.: Comparing the diurnal and seasonal variabilities of atmospheric and surface urban heat islands based on the Beijing urban meteorological network, J. Geophys. Res.-Atmos., 122, 2131-2154, https://doi.org/10.1002/2016JD025304, 2017.

Wang, X., Westerdahl, D., Wu, Y., Pan, X., and Zhang, K. M.: Onroad emission factor distributions of individual diesel vehicles in and around Beijing, China, Atmos. Environ., 45, 503-513, https://doi.org/10.1016/j.atmosenv.2010.09.014, 2011.

Wang, Y., Bao, S., Wang, S., Hu, Y., Shi, X., Wang, J., Zhao, B., Jiang, J., Zheng, M., Wu, M., Russell, A. G., Wang, Y., and Hao, J.: Local and regional contributions to fine particulate matter in Beijing during heavy haze episodes, Sci. Total Environ., 580, 283-296, https://doi.org/10.1016/j.scitotenv.2016.12.127, 2017.

Wang, H., Peng, Y., Zhang, X., Liu, H., Zhang, M., Che, H., Cheng, Y., and Zheng, Y.: Contributions to the explosive growth of $\mathrm{PM}_{2.5}$ mass due to aerosol-radiation feedback and decrease in turbulent diffusion during a red alert heavy haze in BeijingTianjin-Hebei, China, Atmos. Chem. Phys., 18, 17717-17733, https://doi.org/10.5194/acp-18-17717-2018, 2018.

Wang, N., Lyu, X., Deng, X., Huang, X., Jiang, F., and Ding, A.: Aggravating $\mathrm{O}_{3}$ pollution due to $\mathrm{NO}_{x}$ emission control in eastern China, Sci. Total Environ., 677, 732-744, https://doi.org/10.1016/j.scitotenv.2019.04.388, 2019.

Wu, B., Shen, X., Cao, X., Yao, Z., and Wu, Y.: Characterisation of the chemical composition of $\mathrm{PM}_{2.5}$ emitted from on-road China III and China IV diesel trucks in Beijing, China, Sci. Total Enviro., 551-552, 579-589, https://doi.org/10.1016/j.scitotenv.2016.02.048, 2016.

Wu, R., Li, J., Hao, Y., Li, Y., Zeng, L., and Xie, S.: Evolution process and sources of ambient volatile organic compounds during severe haze event in Beijing, China, Sci. Total Environ., 560561, 62-72, https://doi.org/10.1016/j.scitotenv.2016.04.030, 2016. 
Xu, J., Yang, W., Han, B., Wang, M., Wang, Z., Zhao, Z., Bai, Z., and Vedel, S.: An advanced spatio-temporal model for particulate matter and gaseous pollutants in Beijing, China, Atmos. Environ., 211, 120-127, https://doi.org/10.1016/j.atmosenv.2019.04.011, 2019.

$\mathrm{Xu}$, M., Sbihi, H., Pan, X., and Brauer, M.: Local variation of $\mathrm{PM}_{2.5}$ and $\mathrm{NO}_{2}$ concentrations within metropolitan Beijing, Atmos. Environ., 200, 254-263, https://doi.org/10.1016/j.atmosenv.2018.12.014, 2019.

Yang, D., Zhang, S., Niu, T., Wang, Y., Xu, H., Zhang, K. M., and $\mathrm{Wu}$, Y.: High-resolution mapping of vehicle emissions of atmospheric pollutants based on large-scale, realworld traffic datasets, Atmos. Chem. Phys., 19, 8831-8843, https://doi.org/10.5194/acp-19-8831-2019, 2019.

Zhang, L., Liu, L., Zhao, Y., Gong, S., Zhang, X., Henze, D. K., Capps, S. L., Fu, T.-M., Zhang, Q., and Wang, Y.: Source attribution of particulate matter pollution over North China with the adjoint method, Environ. Res. Lett., 10, 8, https://doi.org/10.1088/1748-9326/10/8/084011, 2015.

Zhang, S., Wu, Y., Wu, X., Li, M., Ge, Y., Liang, B., Xu, Y., Zhou, Y., Liu, H., Fu, L., and Hao, J.: Historic and future trends of vehicle emissions in Beijing, 1998-2020: A policy assessment for the most stringent vehicle emission control program in China, Atmos. Environ., 89, 216-229, https://doi.org/10.1016/j.atmosenv.2013.12.002, 2014.

Zhang, S., Wu, Y., Yan, H., Du, X., Zhang, K. M., Zheng, X., Fu, L., and Hao, J.: Black carbon pollution for a major road in Beijing: Implications for policy interventions of the heavy-duty truck fleet, Transport. Res. D-Tr. E., 68, 110-121, https://doi.org/10.1016/j.trd.2017.07.013, 2019.

Zhang, Y., Yao, Z., Shen, X., Liu, H., and He, K.: Chemical characterization of $\mathrm{PM}_{2.5}$ emitted from on-road heavyduty diesel trucks in China, Atmos. Environ., 122, 885-891, https://doi.org/10.1016/j.atmosenv.2015.07.014, 2015.

Zhang, X., Zhong, J., Wang, J., Wang, Y., and Liu, Y.: The interdecadal worsening of weather conditions affecting aerosol pollution in the Beijing area in relation to climate warming, Atmos. Chem. Phys., 18, 5991-5999, https://doi.org/10.5194/acp18-5991-2018, 2018.

Zhang, Y., Andre, M., Liu, Y., Wu, L., Jing, B., Mao, H.: Evaluation of low emission zone policy on vehicle emission reduction in Beijing, China, IOP Conf. Ser.: Earth Environ. Sci., 121, 5, https://doi.org/10.1088/1755-1315/121/5/052070, 2018.
Zhang, Z., Zhang, X., Gong, D., Kim, S.-J., Mao, R., and Zhao, $X .:$ Possible influence of atmospheric circulations on winter haze pollution in the Beijing-Tianjin-Hebei region, northern China, Atmos. Chem. Phys., 16, 561-571, https://doi.org/10.5194/acp16-561-2016, 2016.

Zheng, B., Huo, H., Zhang, Q., Yao, Z. L., Wang, X. T., Yang, X. F., Liu, H., and He, K. B.: High-resolution mapping of vehicle emissions in China in 2008, Atmos. Chem. Phys., 14, 9787-9805, https://doi.org/10.5194/acp-14-9787-2014, 2014.

Zheng, B., Zhang, Q., Tong, D., Chen, C., Hong, C., Li, M., Geng, G., Lei, Y., Huo, H., and He, K.: Resolution dependence of uncertainties in gridded emission inventories: a case study in Hebei, China, Atmos. Chem. Phys., 17, 921-933, https://doi.org/10.5194/acp-17-921-2017, 2017.

Zheng, B., Tong, D., Li, M., Liu, F., Hong, C., Geng, G., Li, H., Li, X., Peng, L., Qi, J., Yan, L., Zhang, Y., Zhao, H., Zheng, Y., He, K., and Zhang, Q.: Trends in China's anthropogenic emissions since 2010 as the consequence of clean air actions, Atmos. Chem. Phys., 18, 14095-14111, https://doi.org/10.5194/acp-18-140952018, 2018.

Zheng, G. J., Duan, F. K., Su, H., Ma, Y. L., Cheng, Y., Zheng, B., Zhang, Q., Huang, T., Kimoto, T., Chang, D., Pöschl, U., Cheng, Y. F., and He, K. B.: Exploring the severe winter haze in Beijing: the impact of synoptic weather, regional transport and heterogeneous reactions, Atmos. Chem. Phys., 15, 2969-2983, https://doi.org/10.5194/acp-15-2969-2015, 2015.

Zhong, M., Saikawa, E., Liu, Y., Naik, V., Horowitz, L. W., Takigawa, M., Zhao, Y., Lin, N.-H., and Stone, E. A.: Air quality modeling with WRF-Chem v3.5 in East Asia: sensitivity to emissions and evaluation of simulated air quality, Geosci. Model Dev., 9, 1201-1218, https://doi.org/10.5194/gmd-9-1201-2016, 2016.

Zhou, J., Chen, Y., Zhang, X., and Zhan, W.: Modelling the diurnal variations of urban heat islands with multisource satellite data, Int. J. Remote, 34, 7568-7588, https://doi.org/10.1080/01431161.2013.821576, 2013. 